\title{
Reactivity of calcined cement raw meals for carbonation
}

by

J. Plou*, I. Martinez, G. Grasa, R. Murillo

Instituto de Carboquímica, ICB-CSIC

M. Luesma Castán 4, 50018 Zaragoza, Spain

Telephone: +34976733977

Fax: +34976733318

e-mail:jplou@icb.csic.es

*corresponding author 


\begin{abstract}
In this work, the suitability of two raw meals from cement manufacture was evaluated for use as $\mathrm{CO}_{2}$ sorbents. The evolution of their $\mathrm{CO}_{2}$ carrying capacity for the initial cycles was determined as a function of calcination conditions, and the Random Pore Model was applied to determine the kinetic parameters of the materials for carbonation. It was observed that the $\mathrm{CO}_{2}$ carrying capacity of the materials was totally dependent on reaction surface, which varies significantly with the calcination conditions (in terms of temperature and partial pressure of $\mathrm{CO}_{2}$ ). The presence of species other than $\mathrm{CaO}$ affected material sorption capacity but had no bearing on reaction kinetics. The calcined raw meal was able to reach maximum conversion in the short reaction times typical of entrained flow reactors, and the dependence of the critical $\mathrm{CaCO}_{3}$ product layer formed on $\mathrm{CaO}$ with reaction temperature was estimated.
\end{abstract}

Keywords: cement industry, $\mathrm{CO}_{2}$ capture, carbonation, raw meal, calcium looping 
Graphical abstract

The initial reaction rate of calcined raw meals do not depend on the surface area. This is shown in different material with different textural properties and their kinetics determination. Surface area determines the critical conversion $\mathrm{X}_{\mathrm{k}-\mathrm{D}}$ and the behaviour of the diffusional controlled reaction rate along the cycles.
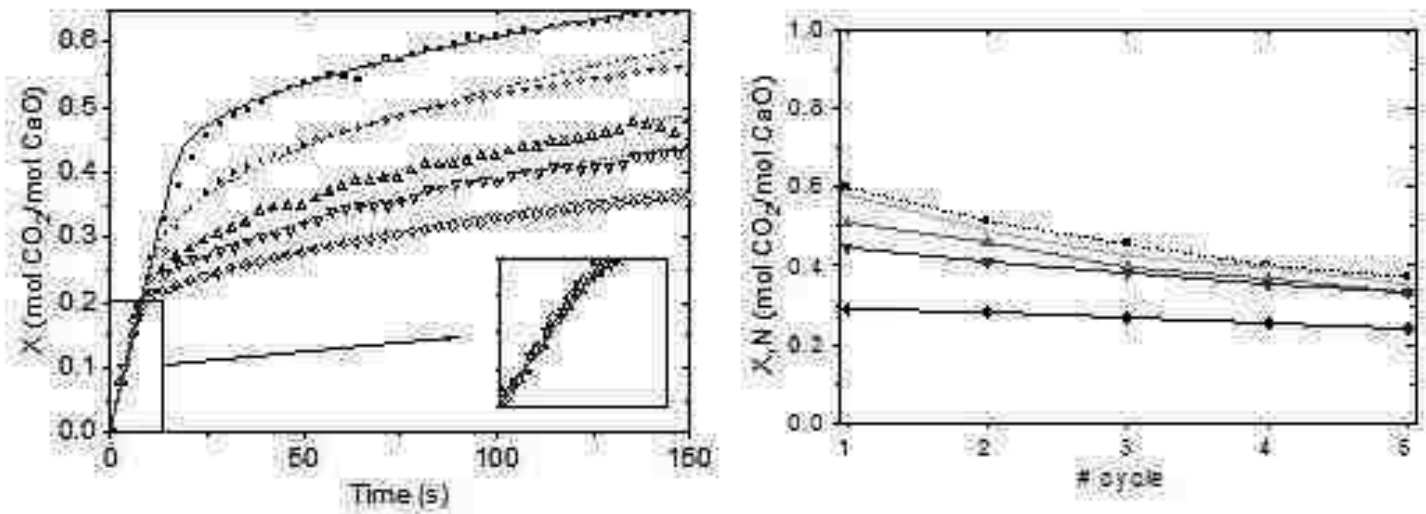


\section{INTRODUCTION}

From the perspective of sustainability, major efforts are being made to reduce greenhouse gases (GHGs), including carbon dioxide. Industry is responsible for 7\% of non-energyrelated anthropogenic $\mathrm{CO}_{2}$ emissions released into the atmosphere [1]. One of the sources is cement production, which accounts for $5 \%$ of total emissions into the atmosphere [2]. The demand for cement is expected to increase in the coming years [3], and therefore it is important to act in order to reduce $\mathrm{CO}_{2}$ emissions in the production processes. Standard cement production comprises several stages. Firstly, a blend of limestone, silica, iron and alumina is crushed to a fine powder called raw meal $(\mathrm{dp}<100 \mu \mathrm{m})$. The raw meal is fed into a system of suspension preheaters consisting of a series of 4-stage cyclones. During this step, the energy released by the counter-flow of exhaust gases from the kiln raises the temperature of the solids to $800^{\circ} \mathrm{C}$. The solid enters the calciner and the raw meal is decarbonised with the energy obtained from the hot air exhausted from the kiln and additional fuel combustion.. The flow of raw meal continues to a rotary kiln where it is heated by burning fuel. The powder achieves temperatures up to $1500^{\circ} \mathrm{C}$, producing hot cement. Due to the metastability of the aluminosilicates, the cement must be cooled quickly in order to retain these in the final product. During this process, $\mathrm{CO}_{2}$ is released by calcination of the calcium carbonate and fuel combustion. Approximately $2 / 3$ of the emissions are associated with raw meal calcination and are inherent to the process. Therefore, although several strategies have been proposed to reduce carbon emissions, such as more efficient use of fuel and the use of alternative fuels [4], only $\mathrm{CO}_{2}$ capture and storage (CCS) would be capable of achieving the strict control of $\mathrm{CO}_{2}$ emissions required.

The post-combustion calcium looping $(\mathrm{CaL})$ process is one of the most promising technologies for $\mathrm{CO}_{2}$ capture to have been developed at MW scale and has been 
implemented in La Pereda integrated in a coal power plant $\left(1.7 \mathrm{MW}_{\text {th }}\right)$, and by TUDarmstadt $\left(1 \mathrm{MW}_{\text {th }}\right)$, and ITRI, integrated in the Cement Taiwan Company plant (1.9 $\mathrm{MW}_{\text {th }}$ [5-12]. This technology is based on the capacity of calcium-based sorbents to react with $\mathrm{CO}_{2}$ from a gas stream in a carbonator reactor [13-17] and the calcination of the formed $\mathrm{CaCO}_{3}$ to produce a concentrated $\mathrm{CO}_{2}$ stream in an oxy-fired calciner. A number of works have identified possible synergies of CaL through simulation works or laboratory-scale studies: the use of $\mathrm{CaO}$ as regenerable $\mathrm{CO}_{2}$ sorbent in the $\mathrm{CaL}$ unit ensures that additional chemical substances do not have to be used, as it is obtained from the same raw material used for clinker production; modifications to key units (rotary kiln and clinker cooler) in existing conventional plants are minimum and the energy required for regenerating the sorbent could be recovered in a steam cycle, which can compensate for the consumption of electricity required in the $\mathrm{CaL}$ process (i.e. $\mathrm{O}_{2}$ production and $\mathrm{CO}_{2}$ compression) $[14,15,17-24]$. There are two main approaches for integrating CaL systems into cement production plants: a tail-end CaL process configuration and the integration of the $\mathrm{CaL}$ in the pre-heating tower $[25,26]$. In the first option, the CaL reactors treat the gases at the exit of the clinker burning line and the $\mathrm{CaL} \mathrm{CO}_{2}$ capture unit follows the standard configuration comprising two circulating fluidised bed reactors. In this way, the $\mathrm{CO}_{2}$ gas stream produced in the rotary kiln is directed to the carbonator reactor after passing through the pre-calciner and pre-heating tower from the cement process. The $\mathrm{CaCO}_{3}$ formed in the carbonator is decomposed in the calciner operating in oxy-fuel mode, requiring the $\mathrm{CaL}$ unit an air separation unit. The purge from the $\mathrm{CaL}$ is further ground and mixed with additives to produce the raw meal. The most highly integrated option includes the use of raw meal as feedstock in the CaL system and operates with a heavy purge. Romano et al. [20] proposed feeding the finely ground raw meal directly into a suspension preheater in which hot gas and the cold solids come into contact 
sequentially inside risers and are then separated in cyclones that heat the solids up to 650 ${ }^{\circ} \mathrm{C}$. The preheated raw meal is sent to the oxy-fuel calciner at about $920{ }^{\circ} \mathrm{C}$, in which the purge of calcined raw meal is high, around $55 \%$, and then introduced directly into the rotary kiln. The rest of the sorbent is looped back into a certain part of the suspension preheater acting as a carbonator, capturing the $\mathrm{CO}_{2}$ from the flue gas exiting the rotary kiln. One of the key points of the integrated process is that the heavy purge is necessary in order to feed the cement production process, causing the sorbent to undergo a small number of cycles. Moreover, a variation of this integrated scheme proposes the use of entrained flow reactors for the carbonation unit and has been studied in the work of De Lena et al. (Figure 1 represents a simplified scheme) [25,27]. Given the small particle size of the raw meal, which is classified as Geldart A powder (typical dp 50 $\mu \mathrm{m}$ ) or Geldart C powder $\left(\mathrm{d}_{\mathrm{p}}<20 \mu \mathrm{m}\right)$ [28], an entrained flow reactor is more suitable in contrast to the standard $\mathrm{CaL}$ applications in which the solid is transported into circulating fluidised beds (CFB), as the typical $d_{p}$ is above $100 \mu \mathrm{m}$, corresponding to a Geldart B powder. The solid/gas ratio is low in entrained flow reactors in comparison with CFB reactors and the contact time is in the range of only a few seconds [29].

The use of raw meals as a $\mathrm{CO}_{2}$ sorbent is a relatively recent concept, but it is an interesting alternative to evaluate with the aim of achieving zero emissions for cement manufacturing plants $[14,19,20,22,23,30,31]$. Raw meal is a mixture of fine powdered limestone, silica, alumina and iron oxide and only the $\mathrm{CaO}$ present in the limestone is able to act as the $\mathrm{CO}_{2}$ sorbent. Few studies have analysed the behaviour of raw meal as a $\mathrm{CO}_{2}$ sorbent in $\mathrm{CaL}$ systems; however, experimental results by Pathi et al. [22] show that as the limestone decays with the number of cycles, so does its carrying capacity. These authors reported a correlation between the raw meal BET surface area calcined under different conditions (temperature and $\mathrm{CO}_{2}$ partial pressure) and the $\mathrm{CO}_{2}$ carrying capacity of the material. 
They concluded that, although new phases can be formed during the calcination of raw meal at high temperature and/or in the presence of $\mathrm{CO}_{2}$, such as belite, sintering was the main reason for the reduced $\mathrm{CO}_{2}$ carrying capacity. A recent work by Alonso et al. [32] analysed the effects that calcination conditions and the aggregation level of raw meal components had on their $\mathrm{CO}_{2}$ carrying capacity, recommending an operation window for the calcination process in order to reduce the deactivation of raw meal as $\mathrm{CO}_{2}$ sorbents.

During a standard cement manufacturing plant process, the raw meal is converted into clinker in two steps: calcination and clinkering. Calcination needs a temperature of $900^{\circ} \mathrm{C}$ for decarbonisation to take place. Clinkering, the subsequent step, requires the temperature to be increased up to $1500{ }^{\circ} \mathrm{C}$ in order to generate various solid-solid reactions and produce diverse calcium silicates and aluminates. Dicalcium silicate, or belite, starts to form at a calcination temperature of $900{ }^{\circ} \mathrm{C}$, and this has been proved to be inert for $\mathrm{CO}_{2}$ capture $[32,33]$. Therefore, calcination conditions in the $\mathrm{CaL}$ process will determine the carrying capacity of the sorbent in relation to the amount of free $\mathrm{CaO}$ and the textural properties. In the works of Pathi et al. [22] and Alonso et al. [32], belite is detected (but not quantified) when the raw meal is calcined at temperatures over $900{ }^{\circ} \mathrm{C}$ and/or in presence of $\mathrm{CO}_{2}$ and steam.

A critical aspect for the design of entrained flow reactors is the reactivity of the materials under relevant conditions for the process, which include short residence times and the existence of a temperature profile along the reaction path. Different expressions to describe the behaviour of the carbonation reactions of $\mathrm{CaO}$-based materials have been proposed in the literature through the diverse solid-gas model [34-39]. The reaction consists of two stages: a fast stage followed by an extremely slow one. As the reaction depends heavily on surface area, a model based on the pore distribution was proposed by Sun et al. [38] in which the only fitted parameter is solid-state diffusivity, $D_{p}$, and where 
pore distribution is taken as an initial value. Li et al. [37] proposed a model that calculates a $\mathrm{CaCO}_{3}$ island distribution over the surface that depends on temperature and where the fitted parameters are the chemical reaction rate coefficient $(\mathrm{k})$, surface diffusion coefficient $\left(D_{s}\right)$ and island size distribution $\left(N_{e}\right)$. The results were validated with an atomic force microscope (AFM) in which the islands were directly measured [40]. Stendardo et al. [41] describes the behaviour of carbonation with a shrinking core model applied to the particles and a diffusion coefficient that changes non-abruptly throughout the conversion of the particle. As conversion proceeds, the resistance to diffusion of the $\mathrm{CO}_{2}$ through the layer increases and is represented by an exponential decay equation.. The random pore model (RPM) has been successfully used in several works [34$36,42,43]$ and the two stages are fully explained by intrinsic kinetic parameters. In this case, the pores are randomly distributed and related only to a structural parameter based on geometry. Variations of the RPM have been proposed in the literature to model the carbonation of $\mathrm{CaO}$-based materials that have undergone multiple reaction cycles $[34,44]$. In order to apply these models, three main parameters are required with which to describe the evolution of $\mathrm{CaO}$ conversion: the intrinsic kinetic parameter $\left(\mathrm{k}_{\mathrm{s}}\right)$, product layer diffusion coefficient (D) and the critical mean product layer $\left(\mathrm{h}_{\mathrm{k}-\mathrm{D}}\right)$. In the literature, the thickness of this layer is determined in a short range of carbonation temperatures ranging between $600^{\circ} \mathrm{C}$ and $700^{\circ} \mathrm{C}$, and its value varies from 30 to $50 \mathrm{~nm}[34,39,42,45,46]$. The dependency of the carbonation reaction with respect to crystallite size was studied by Biasin et al. [47]. Instead of a uniform product layer, a formation of "conically shaped product islands" was proposed with a size varying between 20 and $150 \mathrm{~nm}$. Li et al. [37] developed a rate equation theory for the carbonation reaction, through which they described the growth of $\mathrm{CaCO}_{3}$ islands as a function of temperature and that a higher carbonation temperature led to higher conversion during the fast reaction stage. 
This work aimed to determine the parameters that mostly affect the reactivity of commercial raw meals for the carbonation of $\mathrm{CaO}$, placing special emphasis on short reaction times and evaluating the reaction within a wide range of temperatures $\left(450^{\circ} \mathrm{C}\right.$ to $700^{\circ} \mathrm{C}$ ) as the reactor was adiabatic in design, and therefore a distribution of temperatures could occur while the solids were fed in and flowed through the reactor. The experimental results were fitted with the previously used RPM, as the model describes the evolution of sorbent conversion with time [34]. Additionally, an expression that varies with temperature for the critical product layer wasproposed. $\mathrm{CO}_{2}$ carrying capacity was strongly affected by the textural properties (surface area and pore distribution) of the sorbent after calcination and the effect of temperature and reaction time was studied. The effect of other minor components (calcium silicates and aluminates) was studied through the determination of free $\mathrm{CaO}$ present in the sample.

\section{EXPERIMENTAL SECTION}

The experimental work presented in this work was devoted to determining the $\mathrm{CO}_{2}$ carrying capacity and kinetic parameters for the $\mathrm{CaO}$ carbonation of raw meal materials with different textural properties and/or in presence of belite. Therefore, two different raw meals (RM-1 and RM-2) were calcined in a furnace under diverse conditions of temperature and reaction atmosphere to produce a sufficient amount of material for textural and structural characterization Different analytical techniques were used to determine the textural properties of the calcined and fresh raw meals. Inductively Coupled Plasma Optical Emission Spectroscopy (ICP-OES) analysis was used to determine the elemental composition of the fresh samples. BET surface area was determined in a Micrometrics ASAP 2020 instrument according to the ISO 9277 standard. The BET 
surface area is calculated from the physisorption of nitrogen up to a relative pressure of 0.3 and the accuracy of the instrument is $0.01 \mathrm{~m}^{2} / \mathrm{g}$. The pore structure of the samples was determined by Hg porosimetry in a Micromeritics AutoPore V instrument according to the norm ISO 15901. Hg porosimetry is a method of intrusion of the non-wetting substance at high pressure in which the pore distribution is determined. The accuracy of the instrument is $0.04 \mathrm{~mL}$ of $\mathrm{Hg}$. The true density of the samples was obtained by $\mathrm{He}$ pycnometry in a Micromeritics AccuPyc II and the method principle is the displacement of a known He volume by the material volume with an accuracy of $0.03 \%$ of the measured density. The particle diameter of the fresh samples was determined by laser diffraction using the Tornado Dry Powder Module of a Beckman Coulter LS13320 device according to ISO 13320. X-ray diffraction (XRD) analyses were carried out in a Bruker D8 Advanced diffractometer with an instrument alignment accuracy of $0.01^{\circ}$ and according to the UNE-EN-13925 standard. The results were evaluated using specialist software (Diffrac.Suite from Bruker) in order to determine phase composition. Also, various mixtures were prepared containing different concentrations of sand and $\mathrm{CaO}$ and the areas under the peak with highest intensity for $\mathrm{CaO}$ and $\mathrm{SiO}_{2}$ were calculated. A calibration curve representing area versus concentration was obtained and used for the determination of free $\mathrm{CaO}$ in the samples analysed in this work.

In order to determine the $\mathrm{CO}_{2}$ carrying capacity and kinetic parameters of the materials, carbonation/calcination experiments were performed in a thermogravimetric analyser (TGA) designed for the CaL process. The TGA, previously described by Grasa et al. [34], comprised a two-zone furnace in which each zone was set at different temperature. A pneumatic piston moved the furnaces vertically, thus allowing the sample deposited in a handmade platinum sample pan to undergo alternating calcination and carbonation conditions. The reaction gases were regulated by mass flow controllers. In order to avoid 
the effects of interparticle diffusion, $3 \mathrm{mg}$ of raw meal was tested. Moreover, the total flow of the gases was $4.7 \times 10^{-6} \mathrm{~m}^{3} / \mathrm{s}$, making it possible to eliminate any effects of external diffusion. For the cyclic calcination/carbonation tests, the carbonation temperature was set at $650{ }^{\circ} \mathrm{C}$, and a $\mathrm{CO}_{2}$ partial pressure was set at $10 \%$ vol. These operating conditions were selected based on the premise that the initial concentration of the $\mathrm{CO}_{2}$ stream entering the carbonator unit would be $20 \%$, according to the work of Campanari in the Cemcap project [48]. When $90 \% \mathrm{CO}_{2}$ capture efficiencies are expected, the average concentration in the reactor could be considered as $10 \%$ vol. For kinetic parameter determination, the fresh raw meal was placed in the sample holder. Working temperatures were $900{ }^{\circ} \mathrm{C}$ for calcination and between $450{ }^{\circ} \mathrm{C}$ and $700{ }^{\circ} \mathrm{C}$ for the carbonation reaction.

\section{RESULTS AND DISCUSSION}

Two raw meals from two different cement manufacturers were characterized and tested. The material named RM-1 was a natural marl, and the solid named RM-2 was a commercial raw meal, mixed mechanically and consisting of clay, sand and limestone. According to the chemical analysis obtained by ICP (Table 1), both raw meals were observed to be similar in composition and highly resembling the raw meals for leading Portland cements $[49,50]$. As the raw meals were commercial samples, such similarities in composition were to be expected, as they comply with legal regulations (ASTM C150 [51] and EN 197 standards). The difference in the total percentage calculated was due to minority components not included in the chemical analysis. Among these components, gypsum $\left(\mathrm{CaSO}_{4}\right)$ usually appears in standard Portland cements. Additional qualitative analysis in XRD confirmed the presence of elemental sulphur and $\mathrm{CaSO}_{4}$ in the samples, respectively. Particle size analysis of both materials revealed that the natural marl RM-1 
presented an average particle size of $10.65 \mu \mathrm{m}$ compared with the $48.86 \mu \mathrm{m}$ presented by the raw meal prepared by grinding and mechanical mixing.

Table 1. Chemical composition of raw meals and some reference raw meal for Portland cement (PC).

$\begin{array}{ccccc}\text { Material: } & \text { RM-1 } & \text { RM-2 } & \text { PC,1 [49] } & \text { PC,2 [50] } \\ \mathrm{CaO}(\%) & 63.25 & 62.06 & 66.52 & 62-68 \\ \mathrm{SiO}_{2}(\%) & 19.51 & 20.26 & 21.24 & 21-24 \\ \mathrm{Al}_{2} \mathrm{O}_{3}(\%) & 6.08 & 4.45 & 4.61 & 4-8 \\ \mathrm{Fe}_{2} \mathrm{O}_{3}(\%) & 3.23 & 3.15 & 3.23 & 2-5 \\ \mathrm{MgO}(\%) & 0.96 & 1.46 & 2.27 & --- \\ \mathrm{K}_{2} \mathrm{O}(\%) & 1.37 & 1.22 & 0.42 & --- \\ \mathrm{TiO}_{2}(\%) & 0.24 & 0.19 & 0.28 & --- \\ \mathrm{Na}_{2} \mathrm{O}(\%) & 0.32 & 0.04 & 0.35 & --- \\ \mathrm{Total}^{(\%)} & 94.96 & 92.83 & 98.92 & --- \\ \text { LOI* (\%) } & 34.75 & 34.83 & --- & --- \\ \text { Loss on ignition } & & & & \end{array}$

To evaluate the effect that calcination conditions had on the textural and structural properties of the raw meals, two samples of each were calcined in a tubular furnace at $900{ }^{\circ} \mathrm{C}$ for 1 hour: one sample in air, and the second sample in $50 \%$ vol. air $/ 50 \%$ vol. $\mathrm{CO}_{2}$. The materials were characterized by XRD diffractometry (Figure 2 ) in order to determine the existing crystalline phases and any new phase formed via reactions R.1-R.3. There are two competitive reaction paths for obtaining belite, hence reducing the amount of free $\mathrm{CaO}$. The first of these is the direct solid-solid reaction R.1, while the other is the reaction in series R.2 and R.3. Carbonate has a lower melting point than $\mathrm{CaO}$, and consequently R.1 is supposed to be faster than R.3. According to the spectra, the main phase was $\mathrm{CaO}$, followed by $\mathrm{SiO}_{2}$ with small amounts of belite $\left(\mathrm{Ca}_{2} \mathrm{SiO}_{4}\right)$. The mass concentration of $\mathrm{SiO}_{2}$ in both samples prior to calcination was very similar, but after calcination, the $\mathrm{SiO}_{2}$ peak at $26.7^{\circ}$ was lower in the RM-1 sample. In contrast, the peak at $41.2^{\circ}$ corresponding to 
$\mathrm{Ca}_{2} \mathrm{SiO}_{4}$ presented higher intensity in this sample. This indicates that the conversion to $\mathrm{Ca}_{2} \mathrm{SiO}_{4}$ was higher than for the $\mathrm{RM}-2$ sample and it could have taken the form of reactions R.1 or R.3. The RM-1 powder had a smaller particle size than the RM-2 sample (Figure 3), so the solid-solid reaction between $\mathrm{CaO}$ and $\mathrm{SiO}_{2}$ was better for the $\mathrm{RM}-1$ sample as it presented a higher contact area.

R.1

R.3

BET analysis of the calcined materials showed a clearly lower surface area for the calcined RM-1 sample $\left(3.6 \mathrm{~m}^{2} / \mathrm{g}\right)$ with respect to calcined $\mathrm{RM}-2$ sample $\left(6.6 \mathrm{~m}^{2} / \mathrm{g}\right)$, indicating that, despite the low amount of belite formed, the natural marl has been affected by the sintering phenomenon during the calcination.

Given the results of the textural analysis (lower BET surface area and higher belite formation), a lower $\mathrm{CO}_{2}$ carrying capacity was expected for the natural marl. In order to corroborate this, fresh samples of both raw meals underwent calcination/carbonation cycles in the TGA described in the experimental section. The experimental conditions that served for comparison of the raw meal performance included calcination in air at 875 ${ }^{\circ} \mathrm{C}$ and carbonation in $10 \% \mathrm{CO}_{2}$ vol. in air for 5 minutes at $650{ }^{\circ} \mathrm{C}$.

Figure 3 represents the evolution of the $\mathrm{CO}_{2}$ carrying capacity of the materials with the number of reaction cycles, expressed as $\mathrm{mol} \mathrm{CO}_{2}$ reacted $/ \mathrm{mol} \mathrm{CaO}$ in the material (according to ICP analysis). The decay observed was in agreement with the results published in the literature on cement raw meals [22,32]. The conversion presented by RM-1 was lower than $20 \%$ on coming out of the first cycle, and its $\mathrm{CO}_{2}$ carrying capacity 
decreased throughout the cycles. RM-2 sample conversion started from $60 \%$, as can be seen in the inlet graph. In comparison with the theoretical evolution of the capture capacity found in the literature [13], RM-2 conversion is nearly $80 \%$ of the theoretical curve, whereas the RM-1 sample fits to $30 \%$ of the theoretical curve. Pathi et al. [22] studied the effect of different components in synthetic raw meals by mixing $\mathrm{CaO}$ with $\mathrm{Al}_{2} \mathrm{O}_{3}, \mathrm{SiO}_{2}$ or $\mathrm{Fe}_{2} \mathrm{O}_{3}$ and found that the $\mathrm{CO}_{2}$ carrying capacity decreased on coming out of the first cycle in all cases. These authors attributed the decay in sorption capacity to the loss of surface area produced by the new phases formed between the main species and also to the sintering (as XRD revealed an increase in the $\mathrm{CaO}$ crystallite size owing to increasing calcination temperature and/or increasing $\mathrm{CO}_{2}$ in the calcination atmosphere). According to these authors, the presence of other raw meal components, especially $\mathrm{Al}_{2} \mathrm{O}_{3}$ and $\mathrm{Fe}_{2} \mathrm{O}_{3}$, also has a negative effect on the raw meal tendency to sinter. The deactivation observed in the $\mathrm{CO}_{2}$ carrying capacity of the raw meals may have occurred for two main reasons: deactivation due to the reduction in reaction surface caused by a sintering phenomenon and/or deactivation due to the loss of active $\mathrm{CaO}$ for the carbonation reaction resulting from reaction with $\mathrm{SiO}_{2}$ (R.1-R.3) or other components present in raw meal. The diffractogram in Figure 2 shows the formation of belite in both raw meals. Although the belite peaks are more intense for the RM-1 sample, it was not possible to quantitatively determine the amount of $\mathrm{Ca}_{2} \mathrm{SiO}_{4}$ in the samples. However, by applying the calibration described in the experimental section, it was possible to determine the percentage of free $\mathrm{CaO}$ present in both calcined samples. RM-1 was shown to have 31 wt $\%$ free $\mathrm{CaO}$, while $\mathrm{RM}-2 \mathrm{had} 41 \mathrm{wt} \%$ free $\mathrm{CaO}$. This corroborates the higher formation of aluminosilicates (belite) for the RM-1 material. $\mathrm{CaO}$ crystallite sizes were determined in the samples RM-1 and RM-2 when calcined with only air (RM-1 and RM-2) and with $\mathrm{CO}_{2}\left(\mathrm{RM}-1 \mathrm{CO}_{2}\right.$ and $\left.\mathrm{RM}-2 \mathrm{CO}_{2}\right)$. The use of $\mathrm{CO}_{2}$ in the calcination increased the size in 
RM-1 from $169.4 \mathrm{~nm}$ to $192.1 \mathrm{~nm}$, and in the case of RM-2 from $124.8 \mathrm{~nm}$ to $142.4 \mathrm{~nm}$. These figures corroborate the BET analysis and the higher sintering experienced by RM1 in relation to RM-2 during calcination. The main differences between materials rely on the smaller average particle size of RM-1, a natural marl, and the slightly higher $\mathrm{Al}_{2} \mathrm{O}_{3}$ content in this material, which is known to favour the sintering of raw meals [22]. The main conclusion drawn from this part of the work is that the contribution of both factors is important to explain the decay in sorption capacity presented by the raw meals tested. From then on, the experimental work to determine the kinetic parameters for the carbonation reaction focused on the RM-2 material. Special attention was paid to materials in which belite formation took place, and therefore not all the $\mathrm{CaO}$ was available for reaction with $\mathrm{CO}_{2}$, and also materials with different textural properties.

To produce samples with different amounts of free $\mathrm{CaO}$ and also different textural properties, RM-2 was calcined at varying temperatures in a furnace. These samples were texturally characterized by means of $\mathrm{Hg}$ porosimetry and BET specific surface area analysis and they underwent carbonation tests in the TGA described in the experimental section (at $650{ }^{\circ} \mathrm{C}$ and $10 \% \mathrm{CO}_{2}$ ). Figure 4 shows the textural characterization of $\mathrm{RM}-2$ calcined at different temperatures, Figure 4 shows BET surface area and pore size distributions. As can be seen, BET surface area diminishes with increasing calcination temperature (from $11.8 \mathrm{~m}^{2} / \mathrm{g}$ at $800{ }^{\circ} \mathrm{C}$ to $4.3 \mathrm{~m}^{2} / \mathrm{g}$ at $900{ }^{\circ} \mathrm{C}$ ). $\mathrm{Hg}$ porosimetry of the samples showed that pore structure of the materials is also affected by calcination conditions (as widely reported in the literature [43,52-54]).

$\mathrm{Hg}$ porosimetry of the samples also revealed changes in the pore size distribution (see Figure 4). The calcination of the material at $800{ }^{\circ} \mathrm{C}$ resulted in a mean pore diameter of $60 \mathrm{~nm}$, and this increased to $130 \mathrm{~nm}$ for the material calcined at $900^{\circ} \mathrm{C}$, because of internal sintering due to the temperature. This phenomenon has been also described in the 
literature [52]. The pore structure of the $\mathrm{CaO}$ sorbents tends to evolve with the increasing number of calcination/carbonation cycles. Typical $\mathrm{CaO}$ values from calcined limestone may vary in the order of tens of $\mathrm{nm}[34,39,52]$. With synthetic sorbents, the pore structure of the materials may depend on the production method, and also, of course, on calcination conditions. By way of example, Zhou et al. [43] found a mean peak at $130 \mathrm{~nm}$ in synthetic sorbents composed of $20 \mathrm{wt} \% \mathrm{Ca}_{9} \mathrm{Al}_{6} \mathrm{O}_{18}$ and $80 \mathrm{wt} \% \mathrm{CaO}$. Liu et al. [53] and Gonzalez et al. [54] reported similar behaviour where the pores in fresh samples were greater than $100 \mathrm{~nm}$; however, after reaction, pores in the range of 20-100 $\mathrm{nm}$ appears in synthetic sorbents of $15 \mathrm{wt} \%$ mayenite $\left(\mathrm{Ca}_{12} \mathrm{Al}_{14} \mathrm{O}_{33}\right)$ and $85 \mathrm{wt} \% \mathrm{CaO}$, and a sorbent containing $83 \mathrm{wt} \% \mathrm{CaO}, 14 \mathrm{wt} \% \mathrm{MgO}$ and $3 \mathrm{wt} \% \mathrm{Ca}_{12} \mathrm{Al}_{14} \mathrm{O}_{33}$, respectively. In general, the more aggressive the calcination conditions (in terms of calcination temperature and/or $\mathrm{CO}_{2}$ partial pressure during calcination), the lower the BET surface area and the larger the average pore diameter.

The XRD diffractogram of the calcined samples are shown in the Figure 5. It is possible to observe that the amount of belite (inlet graph) is higher for the sample calcined at 900 ${ }^{\circ} \mathrm{C}$ and that the XRD data greatly coincide for the samples calcined below $850{ }^{\circ} \mathrm{C}$. According to the calibration described previously, the values of free $\mathrm{CaO}$ do not vary noticeably for the samples calcined up to $875^{\circ} \mathrm{C}$, representing approximately $56-57 \mathrm{wt} \%$ with respect to the calcined sample. In contrast, a decrease is observed for the material calcined at the highest temperature $\left(900^{\circ} \mathrm{C}\right)$, this coincides with a slight increase in the belite peak detected by XRD. In this case, the calculated free $\mathrm{CaO}$ was quantified as 52.2 $\mathrm{wt} \%$. Despite the formation of belite, the intensity of the peak reveals that it is a minor phase. It can therefore be stated that, in this case, sintering was mainly responsible for the loss in carrying capacity and not the formation of belite, which decreases the total amount of free $\mathrm{CaO}$. 
To evaluate any effect of textural properties and the presence of belite on material reactivity, fresh raw meal samples calcined in the furnace at different temperatures (ranging from $800{ }^{\circ} \mathrm{C}$ to $900{ }^{\circ} \mathrm{C}$ ) were subjected to a test consisting of 5 carbonation/calcination cycles at $650{ }^{\circ} \mathrm{C}$ and $10 \%$ vol. $\mathrm{CO}_{2}$ in the TGA described in the experimental section. Calcination in the subsequent cycles (2 to 5) was performed at 900 ${ }^{\circ} \mathrm{C}$ in air in the TGA in order to obtain significant belite formation, as this was relevant for the active $\mathrm{CaO}$ present in the raw meal.

Figure 6 (a) shows $\mathrm{CaO}$ molar conversion after 5 minutes of carbonation during every cycle. As can be seen in the Figure, the initial sintering (and higher belite formation) caused by calcination in the furnace has a significant effect on the $\mathrm{CO}_{2}$ carrying capacity present the materials in the first and consecutive cycles. For example, the sample whose first calcination in the furnace was performed at $900{ }^{\circ} \mathrm{C}$ presents very low conversion on coming out of the first cycle, but its decline in activity is reduced as the number of reaction cycles increases. According to the XRD (Figure 5) and the data from Table 2, it presents the highest belite content and lowest percentage of free $\mathrm{CaO}$. In contrast, the samples calcined at lower temperature in the tube furnace showed better performance during the first carbonation, but higher decay with the reaction cycles.

The experimental curves for the first carbonation (expressed in terms of $\mathrm{mol} \mathrm{CO}_{2} / \mathrm{mol}$ $\mathrm{CaO}$ in Figure 6 (b)) show the typical conversion curves that have been widely described in the literature for the reaction of $\mathrm{CaO}$ with $\mathrm{CO}_{2}$, where the two well-known reaction stages $[22,34,42,45,53,55-57]$ can be observed, due to control by the chemical reaction during the initial reaction stage, followed by a second, slower reaction stage governed by a combined control between the chemical reaction and $\mathrm{CO}_{2}$ diffusion through the product layer formed $[39,42,46]$. Finally, there should be a third reaction stage where the product 
layer thickness is well developed and the kinetic constant no longer affects the carbonation reaction rate $[34-36,42,43,58,59]$.

As determined via XRD, the intensity of the characteristic peaks that reveal the presence of belite shows differences among the materials. As previously described, it was not possible to quantify this species, although its presence did not seem to have any effect on the reactivity of $\mathrm{CaO}$ with $\mathrm{CO}_{2}$, given that the initial slope in the conversion curves shown in Figure 6 (b) strongly coincides with the samples calcined at different temperatures. This finding is in agreement with recent studies on the effect that the inert support had on carbonation kinetics of synthetic $\mathrm{CaO}$-based sorbents [44]. Figure 6 (b) shows that the samples are able to achieve a $20 \%$ conversion in the initial 10 seconds, and that the main difference between reaction curves is the conversion at which the transition between reaction stages takes place. This has been related to the formation of a product layer of $\mathrm{CaCO}_{3}$ on the $\mathrm{CaO}$ surface.

To determine the kinetic parameters governing the carbonation reaction for cement raw meals, the model developed by Bhatia and Perlmutter [36] was applied. This model has been widely described in the literature [34-36,44]. Bhatia and Perlmutter developed a general expression (equation 1) for the rate of fluid-solid reactions that included diffusion effects $[35,36,42,58]$. This model has been successfully applied to different CaO-based sorbents $[34,43,46,59,60]$.

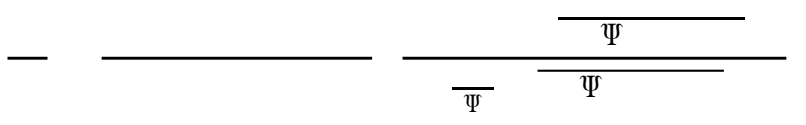

Eq.1

The RPM assumes a distribution of cylindrical pores defined by a unique parameter, $\Psi$. The value is obtained by applying $\mathrm{Hg}$ porosimetry to equations $2-5$. $\mathrm{S}_{0}$ corresponds to the initial surface area per unit of volume; $\mathrm{L}_{0}$ is the initial total pore length and $\varepsilon$ the 
porosity. The value of the structural parameter (Table 2) is similar to the work by Grasa et al. [34].

It is possible to simplify the general rate expression at low conversions in which the reaction is controlled by the chemical reaction. $\beta$ is a modified Biot number and the value is negligible at the beginning of the reaction. Consequently, the resulting expression (equation 6) is used to derive the intrinsic kinetic constant $\mathrm{k}_{\mathrm{s}}$. After the critical product layer is formed and the reaction passes to the second regime, the Biot number changes to a higher value and the expression is simplified into equation 7 . The value of the apparent product layer diffusion coefficient $D_{p}$ is obtained using this expression. The effective diffusion coefficient is the result of applying equation 8 .

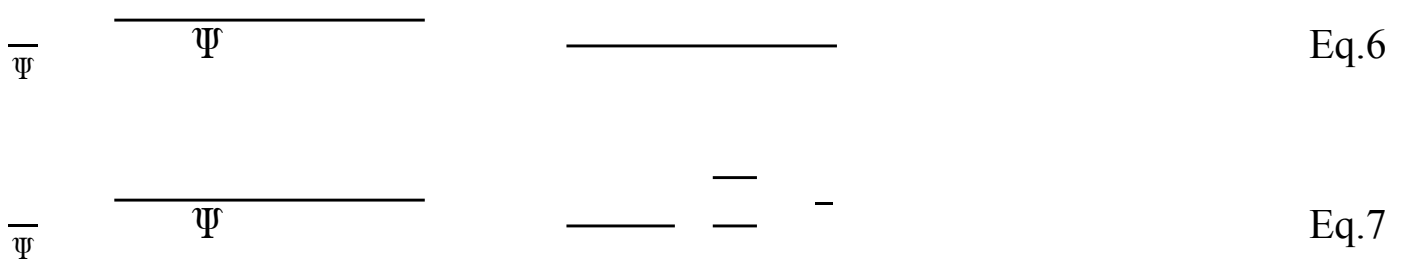

Eq. 8

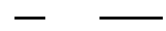

Eq.9 
As a first attempt, the initial reaction rate (equation 10), consistent with a RPM at conversion 0 [36], was applied to estimate the reaction rate experienced by the materials at the moment when there is no product layer.

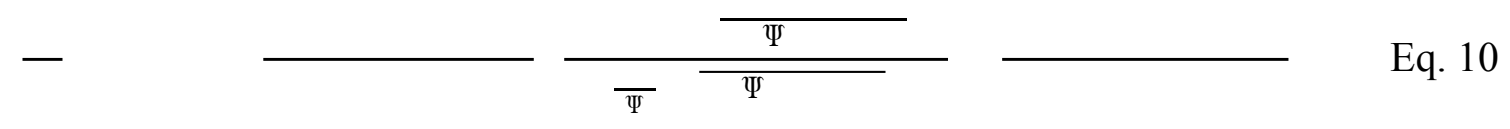

The values extracted from Figure 6 (b) are represented versus the reaction surface corresponding only to $\mathrm{CaO}$ (extracted from textural characterization of the samples and the molar volumes of $\mathrm{CaO}$ and sample) in Figure 7. As can be seen in the figure, the value of the initial reaction rate is between 0.025 and $0.03\left(\mathrm{~s}^{-1}\right)$, close to the values reported in the literature for natural limestones $[34,36]$. These values are almost constant and it can be observed that there is no dependence on the initial reaction rate on the surface.

Experimental data from Figure 6 (b) was useful to determine the conversion level at which the transition between reaction regimes takes place $\left(\mathrm{X}_{\mathrm{k}-\mathrm{D}}\right)$ at $650{ }^{\circ} \mathrm{C}$ for materials presenting different textural properties. This is a key parameter with which to enable detailed modelling of the transition between control by the chemical reaction and the combined control by the chemical reaction and the $\mathrm{CO}_{2}$ diffusion through the $\mathrm{CaCO}_{3}$ product layer formed [34-36,44]. The existence of a critical product layer thickness (and consequently, the existence of $\mathrm{X}_{\mathrm{k}-\mathrm{D}}$ ) was first proposed by Alvarez and Abanades [45], estimated at $50 \mathrm{~nm}$ for a variety of $\mathrm{CaO}$ from natural limestone through multiple calcination/carbonation cycles [39], and experimentally determined in a series of research projects dealing with the reaction of $\mathrm{CaO}$-based materials with $\mathrm{CO}_{2}[37,47,59]$. It has been reported that product layer thickness is highly affected by the composition of the material and particle morphology [44] and also by the temperature and $\mathrm{CO}_{2}$ partial pressure conditions at which the carbonation reaction takes place [59]. In this way, and indirectly from the measured conversion in Figure 6 (a) and the surface area, the product 
layer thickness setting the transition between reaction regimes $\left(\mathrm{h}_{\mathrm{k}-\mathrm{D}}\right)$ can be calculated by means of equation $11[34,39]$ for the RM-2 material tested in this work. The calculated product layer has been referred to as the reaction surface that would correspond to $\mathrm{CaO}$, according to material composition (from ICP analysis and the density of the components, $\mathrm{v}_{\mathrm{CaO}}=63.88 \%$ is the ratio of molar volume of $\mathrm{CaO}$, referred to as the sample molar volume) [46], and a consistent value varying between 119 and $136 \mathrm{~nm}$ has been found (an average value of $127 \mathrm{~nm}$ is taken for later discussion). See Table 2 where the $\mathrm{h}_{\mathrm{k}-\mathrm{D}}$ values are calculated and the textural parameters of the materials are included.

Eq.11

Table 2. Textural and chemical properties of the calcined RM-2

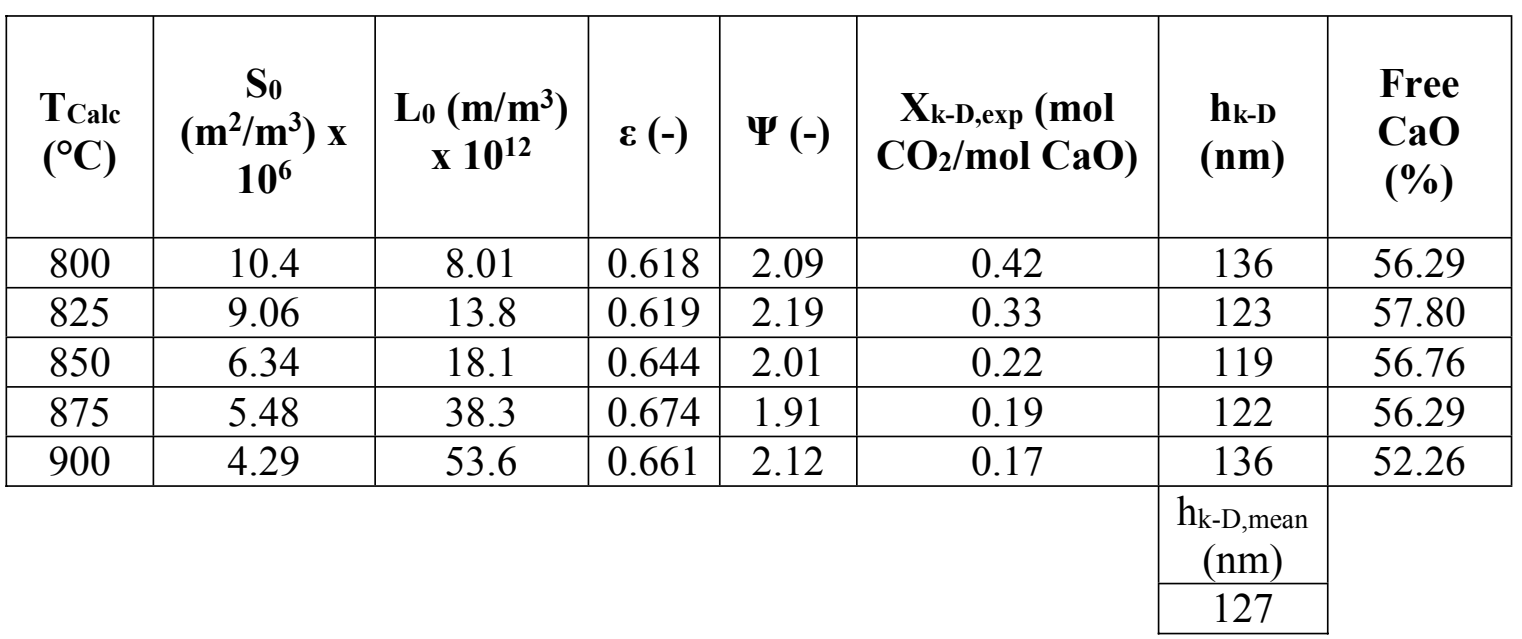

To derive the kinetic data, a wide range of temperatures was used in the carbonation tests. In this way, temperatures between 450 and $700{ }^{\circ} \mathrm{C}$ were selected, as described in the experimental section. Figure 8 (a) shows the evolution of $\mathrm{CaO}$ conversion for the first cycle and at different carbonation temperatures. In this series of tests, the calcination temperature was maintained at $900{ }^{\circ} \mathrm{C}$, so the initial textural properties of the materials were identical. As many as 5 reaction cycles were performed for each test (Figure 8 (b)). 
As can be seen in Figure 8 (a), all the curves present the two differentiated reaction stages as previously described, but it is important to highlight that the conversion level at which the transition between reaction regimes takes place is highly dependent on temperature. Also, this transition between reaction regimes is abrupt, especially at lower temperature, but with temperatures above $650{ }^{\circ} \mathrm{C}$, the transition is smooth and control by chemical reaction and diffusion are in competition. At conditions close to equilibrium, the rates of nucleation and growth are fast and the limiting step is the surface reaction [37]. This surface reaction comprises $\mathrm{CaO}$ and $\mathrm{CaCO}_{3}$ mobility over the surface and is a thermodynamic process in which the temperature favours the overall reaction rate [37]. The left-hand side term in equation 6 was represented vs time for each cycle in every experiment, and the individual values of kinetic constants were determined from the slope of the curves. These kinetic constants were represented in an Arrhenius form and the values of $\mathrm{k}_{\mathrm{so}}$ and $\mathrm{E}_{\mathrm{A}}$ were determined (included in Figure 9). From the experimental data, it was consistently observed at every temperature that carbonation in any cycle presented no differences in terms of the kinetic parameters determined. Moreover, it was possible to describe the evolution of $\mathrm{CaO}$ conversion during any cycle by taking into account the corresponding surface area at every cycle using equation 9 and the kinetic parameters $\mathrm{k}_{\mathrm{s}}$ and $\mathrm{D}$ obtained in the fitting of the first cycle. The change in available surface at the beginning was very sensitive to sintering, so the material coming out of the second cycle was similar to highly cycled materials. In order to diminish the error at this point, a differential determination of $\mathrm{S}_{\mathrm{N}}$ is preferable. Figure 8 (b) shows the experimental curves for consecutive cycles for the series performed at $650^{\circ} \mathrm{C}$. As can be seen, the main difference between the curves is the conversion level at which the transition between regimes takes place, and this is related to the progressive loss in reaction surface with the increasing number of carbonation/calcination cycles. 
Figure 9 shows an Arrhenius plot of the $\mathrm{k}_{\mathrm{s}}$ and D values obtained from equations 6 and 7 , respectively. The surface area, $\mathrm{S}_{0} \cdot \mathrm{v}_{\mathrm{CaO}}$, used in the calculations at first cycle is $3.50 \times 10^{6}$ $\mathrm{m}^{2} / \mathrm{m}^{3}$ and was calculated from the $\mathrm{Hg}$ porosimetry and $\mathrm{CaO}$ volume ratio. This area is approximately one order below the values obtained in calcined limes [34], and the obtained value for the kinetic parameter $\mathrm{k}_{\mathrm{s}}$ found at $650{ }^{\circ} \mathrm{C},\left(0.37 \times 10^{-5} \mathrm{~m}^{4} / \mathrm{kmol} \mathrm{s}\right)$, was also one order higher than the values reported by Grasa et al. [34] $\left(0.05 \times 10^{-5} \mathrm{~m}^{4} / \mathrm{kmol} \mathrm{s}^{2}\right.$ and Bhatia and Perlmutter [36] $\left(0.06 \times 10^{-5} \mathrm{~m}^{4} / \mathrm{kmol} \mathrm{s}\right)$. Despite these differences, as described a few paragraphs previously, the initial reaction rate estimated for the calcined raw meal was similar to those reported in the literature for $\mathrm{CaO}$ based sorbents and the initial delta conversion at $615^{\circ} \mathrm{C}$ was $0.037 \mathrm{~s}^{-1}$ in this work. Grasa et al. reported values of $0.032 \mathrm{~s}^{-1}$ and $0.033 \mathrm{~s}^{-1}$ in two limestones [34], and Bhatia and Perlmutter reported 0.041 $\mathrm{s}^{-1}$ [36] at $615{ }^{\circ} \mathrm{C}$. Lopez et al. obtained values in a range of 0.036 and $0.039 \mathrm{~s}-1$, for a fine powder of synthesized samples with $\mathrm{CaO} / \mathrm{MgO}$ molar ratios ranging from 0.5 to 2 . In all cases, despite the composition or the surface of the solid, the initial reaction rate was in close agreement. To account for this finding, the RPM equation was modified with the purpose of comparison and equation 12 was obtained from equation 1 . Here, a kinetic parameter $\mathrm{k}_{\mathrm{CaO}}$ that accounts for the product " $\mathrm{k}_{\mathrm{s}} \cdot \mathrm{S}_{0} /(1-\varepsilon)$ " was included. Finally, $\mathrm{k}_{\mathrm{CaO}}$ had a mean value of $30 \mathrm{~m}^{3} / \mathrm{kmol} \mathrm{s}$ at $615{ }^{\circ} \mathrm{C}$. The Arrhenius plot of $\mathrm{k}_{\mathrm{CaO}}$ is represented in Figure 9. The surface area, $\mathrm{S}_{0}$, determines the behaviour of the reaction through the critical conversion $\mathrm{X}_{\mathrm{k}-\mathrm{D}}$ and $\beta$ in the combined control stage.

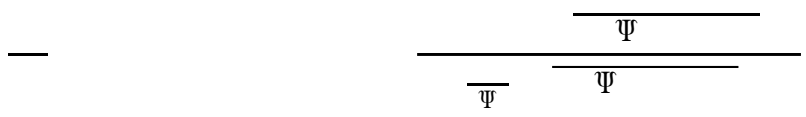

Eq.12

The activation energy for the carbonation reaction obtained in this range of temperatures, $(24.13 \pm 3.6) \times 10^{3} \mathrm{~kJ} / \mathrm{kmol}$, was similar to the values obtained by Sun et al. [46] $(29 \mathrm{~kJ} / \mathrm{mol}$ for limestones and $24 \mathrm{~kJ} / \mathrm{mol}$ for dolomite), Grasa et al. [34] (19 kJ/mol and $21 \mathrm{~kJ} / \mathrm{mol}$ 
for two different limestones) and Lopez et al. [44] (13.4 kJ/mol for synthetic $\mathrm{CaO} / \mathrm{MgO}$ sorbents). Other authors reported zero activation energy, such as Chuant et al. [61], Bhatia and Perlmutter [42], Li et al. [37] and Biasin et al. [47]. Sun et al. [46] proposed that the differences in activation energy were due to material structural properties. In thermodynamic terms, the energy barrier to be broken through involves chemical energy and mechanical structure-related energy [46].

An Arrhenius plot was applied for the apparent diffusion coefficient D and the value of D at $650{ }^{\circ} \mathrm{C}, 5.1 \times 10^{-13} \mathrm{~m}^{2} / \mathrm{s}$, was two orders below that found by Grasa et al. [34], $2.0 \mathrm{x}$ $10^{-15} \mathrm{~m}^{2} / \mathrm{s}$ and $2.5 \times 10^{-15} \mathrm{~m}^{2} / \mathrm{s}$. According to Li et al. [37,40], the effective diffusion coefficient is divided into three terms: grain boundary diffusion $\left(\mathrm{D}_{\mathrm{GB}}\right)$, lattice diffusion $\left(D_{L}\right)$ and surface diffusion $\left(D_{S}\right)$. The surface diffusion $\left(D_{S}\right)$ controls the initial growth in the fast reaction stage. During the diffusion-controlled step, $\mathrm{CO}_{2}$ goes through the defects in the $\mathrm{CaCO}_{3}$ grain boundaries $\left(\mathrm{D}_{\mathrm{GB}}\right)$ and through the product layer $\left(\mathrm{D}_{\mathrm{L}}\right)$; the effective diffusion coefficient being a contribution of both diffusion coefficients $\left(D_{\text {eff }}=f \cdot D_{\mathrm{GB}}+(1-\right.$ f) $\left.\cdot \mathrm{D}_{\mathrm{L}}\right)$. Therefore, both diffusion types control the growth of the $\mathrm{CaCO}_{3}$ produced. In the case of limestones, $\mathrm{CaO}$ is spread over the surface homogenously, but for raw meal, due to the presence of other minor compounds, this oxide is dispersed heterogeneously and the $\mathrm{CaCO}_{3}$ layer produced might not be uniform. Hence, the number of defects over the reaction surface is higher for raw meal than limestones, thus increasing the value of the $\mathrm{D}_{\mathrm{GB}}$ coefficient, which results in an increase in the effective diffusion coefficient. The energy activation, $63.8 \pm 8 \mathrm{~kJ} / \mathrm{mol}$, was very low compared to the work with limes, 163 $\mathrm{kJ} / \mathrm{mol}$ [34] and $178 \mathrm{~kJ} / \mathrm{mol}$ [60]. Bhatia and Perlmutter [42] found two regimes in which the activation energy changes from $88.9 \mathrm{~kJ} / \mathrm{mol}$ to $179.2 \mathrm{~kJ} / \mathrm{mol}$ at $515^{\circ} \mathrm{C}$, and this lower value of the activation energy has also been found in electrical conduction experiments. The ion $\mathrm{CO}_{3}{ }^{-2}$ is accepted as the mobile species, and with regard to raw meals, the defect 
sites and vacancies where the ion could move is higher than in a limestone, due to inert components and impurities. Additionally, Zhou et al. [43] reported an activation energy of $88.7 \mathrm{~kJ} / \mathrm{mol}$ for a synthetic sorbent composed of $80 \% \mathrm{CaO}$ and $20 \% \mathrm{Ca}_{9} \mathrm{Al}_{6} \mathrm{O}_{18}$, citing the main cause to be the morphology and texture of the sorbent. As explained by Li et al. $[37,40]$, the reaction rate in the second step is limited by the surface reaction and is dependent on the number of carbonate islands created over the $\mathrm{CaO}$ surface. Sun et al. [46] explained that the differences in activation energy between a dolomite and a limestone lay in the structure of the particle and the lower strain energy, because of more available space for the growth of the product. Linking both theories, the great difference in energy activation is caused by the voids in the surface of the other components that allow the growth of the carbonate in this zone.

Based on the experimental conversion curves from Figure 8, an effort was also made in this work to correlate the effect that carbonation temperature had on the product layer thickness that sets the onset of the combined controlled regime. The layer at every carbonation temperature was calculated by the equation 11 and the critical conversion was that found from the fitted curve extracted from the Figure 8 . The values obtained in this work were plotted together with the values reported in the literature (Figure 10) $[34,39,44,47,59]$. As an example, an in depth study of the effect of temperature on the critical product layer was conducted in the work by Biasin et al. [47] using synchrotron XRD and the evolution of the crystallite size during the carbonation reaction. When comparing the results of the critical $\mathrm{CaCO}_{3}$ crystallite size reported by Biasin et al. [47], the diameter of the crystallites were found to be similar to the calculated thickness of the layer. Intense research has been carried out to describe the morphology of the $\mathrm{CaCO}_{3}$ layer under diverse conditions $[37,40,42,46,47,62,63]$, but it is possible to assume that the layer is a row of crystallites, which is supported by the theory of the island distribution 
over the surface $[37,40]$. Biasin et al. proposed a linear dependency of the size of $\mathrm{CaCO}_{3}$ crystallite with respect to carbonation temperature. However, an Arrhenius expression is proposed in this work to explain the dependency on temperature. As the thickness of the layer depends on the chemical reaction and the surface reaction, the increase in size is thermodynamically justified because of the surface diffusion of the $\mathrm{CaCO}_{3}$. Despite the thickness of the $\mathrm{CaCO}_{3}$ product, the diffusion of $\mathrm{CO}_{2}$ through the layer is possible at high temperatures and the conversion is noticeable. Activation energy of $38.8 \mathrm{~kJ} / \mathrm{mol}$ has been found to relate to the diffusion (Figure 10). The Grasa et al. and Abanades et al. studies $[34,39]$ state that the critical layer thickness in limestone carbonations varies from 30-42 $\mathrm{nm}$ and 30-64 nm, respectively. In the work of Lopez, the critical layer thickness varies between 57 and $96 \mathrm{~nm}$ depending on the ratio of $\mathrm{CaO} / \mathrm{MgO}$ [44] (values corrected according to $\mathrm{CaO}$ only surface). The differences in thickness, according to work by $\mathrm{Li}$ [37], could be associated with the initial size of the $\mathrm{CaO}$ crystallite, and this will depend on several factors: calcination conditions, material composition, morphology and sorbent synthesis.

Eq, 13

\section{CONCLUSIONS}

Two different raw meal materials were evaluated in this work as $\mathrm{CO}_{2}$ sorbents. The $\mathrm{CO}_{2}$ carrying capacity of the materials was determined by the surface area available for reaction. It was experimentally observed that the calcination conditions had a dramatic effect on textural properties and therefore on material performance. Moreover, the particle size of the raw meals played an important role, due to the reaction between the calcic components and the alumina or silica to form inert species. High temperatures and 
the presence of $\mathrm{CO}_{2}$ favoured this process and, consequently, the free $\mathrm{CaO}$ present in the sample diminished with the temperature. The kinetic parameters for the carbonation reaction of raw meals were determined and the RPM model was successfully applied to describe the evolution of $\mathrm{CaO}$ conversion over time for materials with different textural properties and in presence of belite. The kinetic parameters in the carbonation were determined at temperatures ranging from $450{ }^{\circ} \mathrm{C}$ to $700{ }^{\circ} \mathrm{C}$. Although the raw meal was a mixture of calcium oxide, alumina and silica, the intrinsic kinetics in the initial stage agreed with the literature and therefore there was no observable effect of new phases formed. The activation energy of $24.13 \mathrm{~kJ} / \mathrm{mol}$ was similar to that found by other authors. The activation energy at the stage in which the diffusion of gases through the product layer controls the rate presented a lower value $(63.8 \mathrm{~kJ} / \mathrm{mol})$ with respect to data referring to $\mathrm{CaO}$ from natural limestones and dolomites. The critical product layer thickness formed, which sets the transition between reaction regimes, can be described with an Arrhenius equation with an activation energy of $38.8 \mathrm{~kJ} / \mathrm{mol}$.

\section{$\underline{\text { Acknowledgements }}$}

This work acknowledges the support provided by the Spanish Ministry of Economy, Industry and Competitiveness through its funding of the project ENE2015-68885-C2-2R. The authors also wish to thank the Regional Government of Aragon (DGA) for the support given through the research group support programme.

\section{$\underline{\text { Nomenclature }}$}

$\mathrm{C}$

$\mathrm{CO}_{2}$ concentration $\left(\mathrm{kmol} / \mathrm{m}^{3}\right)$

$\mathrm{C}_{\mathrm{eq}} \quad \mathrm{CO}_{2}$ concentration at equilibrium $\left(\mathrm{kmol} / \mathrm{m}^{3}\right)$ 


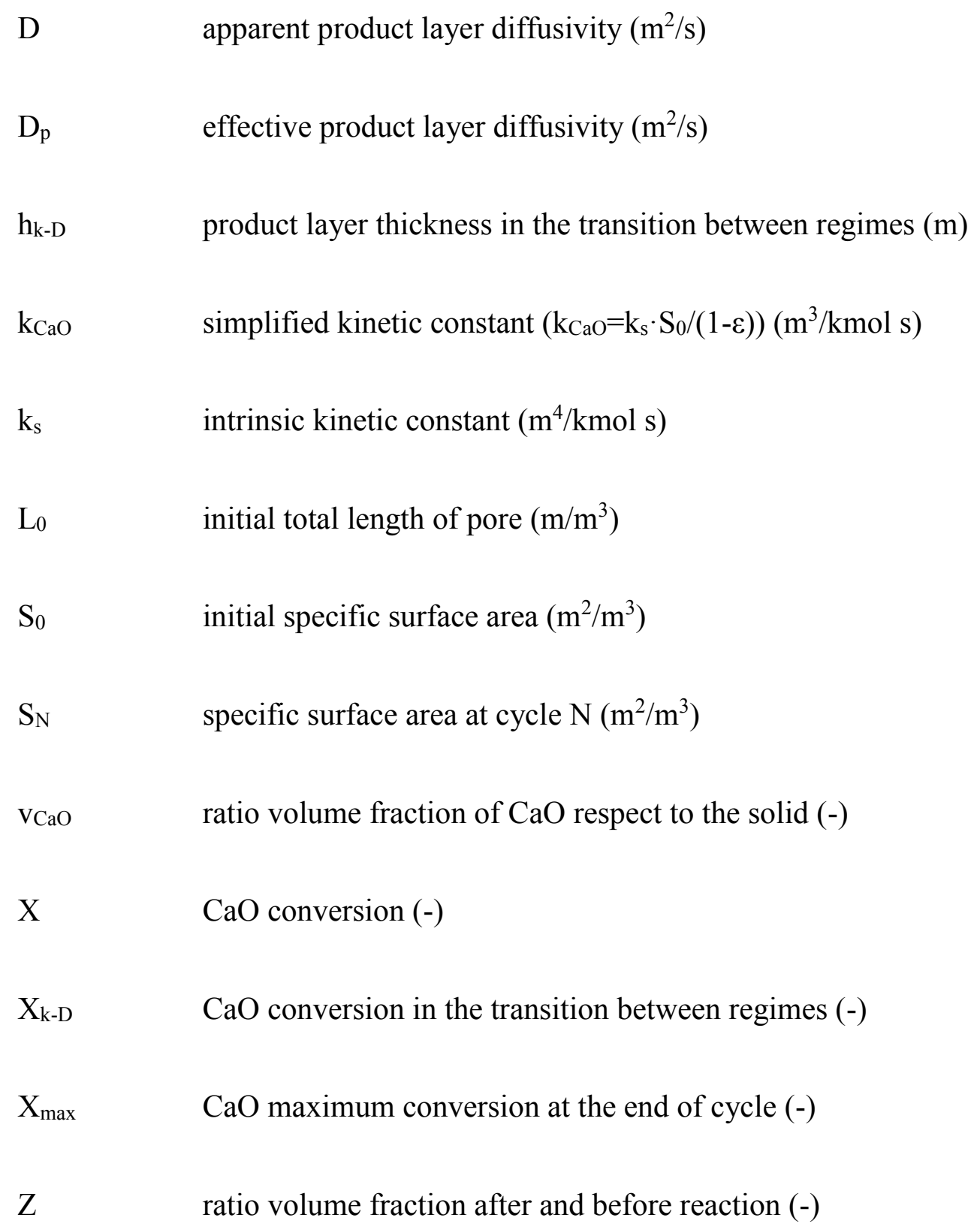

\section{Greek letters}

$\beta \quad$ modified Biot modulus in the random pore model (-)

$\varepsilon \quad$ porosity (-)

$\Psi \quad$ structural parameter (-) 

Acronyms
$\mathrm{CaL} \quad$ Calcium Looping
CFB Circulating fluidised bed
GHG Greenhouse gases
RPM Random pore model
TGA Thermogravimetric analysis

\section{REFERENCES}

[1] F. Birol, CO2 Emissions from Fuel Combustion 2017 - Highlights, Int. Energy Agency. 1 (2017) 1-162. doi:10.1787/co2_fuel-2017-en.

[2] Cembureau, Activity Report 2015, (2016) 2-5. https://cembureau.eu/media/1503/2015activityreport_cembureau.pdf.

[3] M.S. Imbabi, C. Carrigan, S. McKenna, Trends and developments in green cement and concrete technology, Int. J. Sustain. Built Environ. 1 (2012) 194-216. doi:10.1016/j.ijsbe.2013.05.001.

[4] E. Benhelal, G. Zahedi, E. Shamsaei, A. Bahadori, Global strategies and potentials to curb CO2 emissions in cement industry, J. Clean. Prod. 51 (2013) 142-161. doi:10.1016/j.jclepro.2012.10.049.

[5] B. Arias, M.E. Diego, J.C. Abanades, M. Lorenzo, L. Diaz, D. Martínez, J. Alvarez, A. Sánchez-Biezma, Demonstration of steady state CO2 capture in a 1.7 MWth calcium looping pilot, Int. J. Greenh. Gas Control. 18 (2013) 237-245. 
doi:10.1016/j.jiggc.2013.07.014.

[6] M. Alonso, M.E. Diego, C. Pérez, J.R. Chamberlain, J.C. Abanades, Biomass combustion with in situ $\mathrm{CO} 2$ capture by $\mathrm{CaO}$ in a $300 \mathrm{kWth}$ circulating fluidized bed facility, Int. J. Greenh. Gas Control. 29 (2014) 142-152. doi:10.1016/j.ijggc.2014.08.002.

[7] J. Ströhle, M. Junk, J. Kremer, A. Galloy, B. Epple, Carbonate looping experiments in a 1 MWth pilot plant and model validation, Fuel. 127 (2014) 13-22. doi:10.1016/j.fuel.2013.12.043.

[8] M.E. Diego, B. Arias, A. Méndez, M. Lorenzo, L. Díaz, A. Sánchez-Biezma, J.C. Abanades, Experimental testing of a sorbent reactivation process in La Pereda 1.7 MWth calcium looping pilot plant, Int. J. Greenh. Gas Control. 50 (2016). doi:10.1016/j.ijggc.2016.04.008.

[9] M.E. Diego, B. Arias, J.C. Abanades, Evolution of the CO2 carrying capacity of $\mathrm{CaO}$ particles in a large calcium looping pilot plant, Int. J. Greenh. Gas Control. 62 (2017) 69-75. doi:10.1016/j.ijggc.2017.04.005.

[10] M.H. Chang, C.M. Huang, W.H. Liu, W.C. Chen, J.Y. Cheng, W. Chen, T.W. Wen, S. Ouyang, C.H. Shen, H.W. Hsu, Design and experimental investigation of calcium looping process for 3-kWth and 1.9-MWth facilities, Chem. Eng. Technol. 36 (2013) 1525-1532. doi:10.1002/ceat.201300081.

[11] M.H. Chang, W.C. Chen, C.M. Huang, W.H. Liu, Y.C. Chou, W.C. Chang, W. Chen, J.Y. Cheng, K.E. Huang, H.W. Hsu, Design and Experimental Testing of a 1.9MWth Calcium Looping Pilot Plant, Energy Procedia. 63 (2014) 2100-2108. doi:10.1016/j.egypro.2014.11.226. 
[12] S. Turrado, B. Arias, J.R. Fernandez, J.C. Abanades, Carbonation of fine CaO particles in a drop tube reactor, Ind. Eng. Chem. Res. 57 (2018) 13372-13380. doi:10.1021/acs.iecr.8b02918.

[13] G. Grasa, J.C. Abanades, $\mathrm{CO} 2$ Capture Capacity of $\mathrm{CaO}$ in Long Series of Carbonation/Calcination Cycles, Ind. Eng. Chem. Res. 45 (2006) 8846-8851. doi:10.1021/ie0606946.

[14] J. Blamey, E.J. Anthony, J. Wang, P.S. Fennell, The calcium looping cycle for large-scale CO2 capture, Prog. Energy Combust. Sci. 36 (2010) 260-279. doi:10.1016/j.pecs.2009.10.001.

[15] M. Spinelli, I. Martínez, E. De Lena, G. Cinti, M. Hornberger, R. Spörl, J.C. Abanades, C. Becker, R. Mathai, K. Fleiger, V. Hoenig, M. Gatti, R. Scaccabarozzi, S. Campanari, S. Consonni, M.C. Romano, Integration of CaLooping systems for CO2 capture in cement plants, Energy Procedia. 114 (2017) 6206-6214. doi:10.1016/j.egypro.2017.03.1758.

[16] B. Arias, M. Alonso, J.C. Abanades, CO2 Capture by calcium looping at relevant conditions for cement plants: experimental testing in a $30 \mathrm{~kW}$, Ind. Eng. Chem. Res. 56 (2017) 2634-2640. doi:10.1021/acs.iecr.6b04617.

[17] I. Martínez, G. Grasa, J. Parkkinen, T. Tynjälä, T. Hyppänen, R. Murillo, M.C.M.C. Romano, Review and research needs of Ca-Looping systems modelling for post-combustion $\mathrm{CO} 2$ capture applications, Int. J. Greenh. Gas Control. 50 (2016) 271-304. doi:10.1016/j.ijggc.2016.04.002.

[18] N. Rodríguez, M. Alonso, G. Grasa, J.C. Abanades, Process for capturing CO2 arising from the calcination of the $\mathrm{CaCO} 3$ used in cement manufacture, Environ. 
Sci. Technol. 42 (2008) 6980-6984. doi:10.1021/es800507c.

[19] N. Rodríguez, R. Murillo, J.C. Abanades, CO2 capture from cement plants using oxyfired precalcination and/ or calcium looping, Environ. Sci. Technol. 46 (2012) 2460-2466. doi:10.1021/es2030593.

[20] M.C. Romano, M. Spinelli, S. Campanari, S. Consonni, M. Marchi, N. Pimpinelli, G. Cinti, The Calcium looping process for low $\mathrm{CO} 2$ emission cement plants, Energy Procedia. 61 (2014) 500-503. doi:10.1016/j.egypro.2014.11.1158.

[21] D.C. Ozcan, H. Ahn, S. Brandani, Process integration of a Ca-looping carbon capture process in a cement plant, Int. J. Greenh. Gas Control. 19 (2013) 530-540. doi:10.1016/j.ijggc.2013.10.009.

[22] S.K. Pathi, W. Lin, J.B. Illerup, K. Dam-Johansen, K. Hjuler, CO2 capture by cement raw meal, Energy \& Fuels. 27 (2013) 5397-5406. doi:10.1021/ef401073p.

[23] K. Atsonios, P. Grammelis, S.K. Antiohos, N. Nikolopoulos, E. Kakaras, Integration of calcium looping technology in existing cement plant for $\mathrm{CO} 2$ capture: Process modeling and technical considerations, Fuel. 153 (2015). doi:10.1016/j.fuel.2015.02.084.

[24] M.C. Romano, Modeling the carbonator of a Ca-looping process for CO2 capture from power plant flue gas, Chem. Eng. Sci. 69 (2012) 257-269. doi:10.1016/j.ces.2011.10.041.

[25] E. De Lena, M. Spinelli, I. Martínez, M. Gatti, R. Scaccabarozzi, G. Cinti, M.C. Romano, Process integration study of tail-end Ca-Looping process for $\mathrm{CO} 2$ capture in cement plants, Int. J. Greenh. Gas Control. 67 (2017) 71-92. doi:10.1016/j.ijggc.2017.10.005. 
[26] G. Cinti, E. De Lena, M. Spinelli, M. Romano, Design of post combustion capture and integrated calcium looping cement plant systems. CEMCAP project deliverable 12.5., (2018). https://www.sintef.no/projectweb/cemcap/results/.

[27] M. Spinelli, I. Martínez, M.C. Romano, One-dimensional model of entrained-flow carbonator for $\mathrm{CO} 2$ capture in cement kilns by Calcium looping process, Chem. Eng. Sci. 191 (2018) 100-114. doi:10.1016/j.ces.2018.06.051.

[28] D. Geldart, Types of gas fluidization, Powder Technol. 7 (1973) 285-292. doi:10.1016/0032-5910(73)80037-3.

[29] D. Kunii, O. Levenspiel, Fluidization engineering, Elsevier, 2013.

[30] J.R. Fernández, J.C. Abanades, CO2 capture from the calcination of CaCO3 using iron oxide as heat carrier, J. Clean. Prod. 112 (2016) 1211-1217. doi:10.1016/j.jclepro.2015.06.010.

[31] M. Alonso, B. Arias, A. Méndez, F. Fuentes, J.C. Abanades, Screening CO2 capture test for cement plants using a lab scale calcium looping pilot facility, Energy Procedia. 114 (2017) 53-56. doi:10.1016/j.egypro.2017.03.1146.

[32] M. Alonso, Y. Álvarez Criado, J.R. Fernández, J.C. Abanades, CO2 carrying capacities of cement raw meals in calcium looping systems, Energy and Fuels. 31 (2017) 13955-13962. doi:10.1021/acs.energyfuels.7b02586.

[33] B.R. Stanmore, P. Gilot, Review-calcination and carbonation of limestone during thermal cycling for CO2sequestration, Fuel Process. Technol. 86 (2005) 17071743. doi:10.1016/j.fuproc.2005.01.023.

[34] G. Grasa, R. Murillo, M. Alonso, J.C. Abanades, Application of the random pore 
model to the carbonation cyclic reaction, AIChE J. 55 (2009) 1246-1255. doi:10.1002/aic.11746.

[35] S.K. Bhatia, D.D. Perlmutter, A random pore model for fluid-solid reactions : 1. lsothermal, kinetic control, AIChE J. 26 (1980) 379-386.

[36] S.K. Bhatia, D.D. Perlmutter, A random pore model for fluid-solid reactions: 2. Diffusion and transport effects, AIChE J. 27 (1981) 247-254. doi:10.1002/aic.690270211.

[37] Z. Li, H. Sun, N. Cai, Rate equation theory for the carbonation reaction of $\mathrm{CaO}$ with CO2, Energy and Fuels. 26 (2012) 4607-4616. doi:10.1021/ef300607z.

[38] P. Sun, J.R. Grace, C.J. Lim, E.J. Anthony, A discrete-pore-size-distribution-based gas-solid model and its application to the $\mathrm{CaO}+\mathrm{CO} 2$ reaction, Chem. Eng. Sci. 63 (2008) 57-70. doi:10.1016/j.ces.2007.08.054.

[39] D. Alvarez, J.C. Abanades, Determination of the critical product layer thickness in the reaction of $\mathrm{CaO}$ with $\mathrm{CO} 2$, Ind. Eng. Chem. Res. 44 (2005) 5608-5615. doi:10.1021/ie050305s.

[40] Z. Li, F. Fang, X. Tang, N. Cai, Effect of temperature on the carbonation reaction of $\mathrm{CaO}$ with CO2, Energy \& Fuels. 26 (2012) 2473-2482. doi:10.1021/ef201543n.

[41] S. Stendardo, P.U. Foscolo, Carbon dioxide capture with dolomite: A model for gas-solid reaction within the grains of a particulate sorbent, Chem. Eng. Sci. 64 (2009) 2343-2352. doi:10.1016/j.ces.2009.02.009.

[42] S.K. Bhatia, D.D. Perlmutter, Effect of the product layer on the kinetics of the carbon dioxide-lime reaction, AIChE J. 29 (1983) 79-86. 
doi:10.1002/aic.690290111.

[43] Z. Zhou, P. Xu, M. Xie, Z. Cheng, W. Yuan, Modeling of the carbonation kinetics of a synthetic CaO-based sorbent, Chem. Eng. Sci. 95 (2013) 283-290. doi:10.1016/j.ces.2013.03.047.

[44] J.M. López, G. Grasa, R. Murillo, Evaluation of the effect of inert support on the carbonation reaction of synthetic $\mathrm{CaO}$-based $\mathrm{CO} 2$ sorbents, Chem. Eng. J. 350 (2018) 559-572. doi:10.1016/j.cej.2018.05.014.

[45] J.C. Abanades, D. Alvarez, Conversion limits in the reaction of $\mathrm{CO} 2$ with lime, Energy and Fuels. 17 (2003) 308-315. doi:10.1021/ef020152a.

[46] P. Sun, J.R. Grace, C.J. Lim, E.J. Anthony, Determination of intrinsic rate constants of the $\mathrm{CaO}-\mathrm{CO} 2$ reaction, Chem. Eng. Sci. 63 (2008) 47-56. doi:10.1016/j.ces.2007.08.055.

[47] A. Biasin, C.U. Segre, M. Strumendo, $\mathrm{CaCO} 3$ Crystallite evolution during $\mathrm{CaO}$ carbonation: critical crystallite size and rate constant measurement by in-situ synchrotron radiation X-ray powder diffraction, Cryst. Growth Des. 15 (2015) 5188-5201. doi:10.1021/acs.cgd.5b00563.

[48] S. Campanari, G. Cinti, S. Consonni, K. Fleiger, M. Gatti, M. Hoppe, I. Martínez, M. Romano, M. Spinelli, M. Voldsund, Design and performance of CEMCAP cement plant without CO2 capture. CEMCAP project deliverable D4.1, (2016). https://www.sintef.no/projectweb/cemcap/results/.

[49] P.E. Tsakiridis, S. Agatzini-Leonardou, P. Oustadakis, Red mud addition in the raw meal for the production of Portland cement clinker, J. Hazard. Mater. 116 (2004) 103-110. doi:10.1016/j.jhazmat.2004.08.002. 
[50] A. Monshi, M.K. Asgarani, Producing portland cement from iron and steel slags and limestone, Cem. Concr. Res. 29 (1999) 1373-1377. doi:10.1016/S00088846(99)00028-9.

[51] ASTM C150, Standard specification for Portland cement, (2002).

[52] D. Alvarez, J.C. Abanades, Pore-size and shape effects on the recarbonation performance of calcium oxide submitted to repeated calcination/recarbonation cycles, Energy and Fuels. 19 (2005) 270-278. doi:10.1021/ef049864m.

[53] W. Liu, J.S. Dennis, D.S. Sultan, S.A.T. Redfern, S.A. Scott, An investigation of the kinetics of $\mathrm{CO} 2$ uptake by a synthetic calcium based sorbent, Chem. Eng. Sci. 69 (2012) 644-658. doi:10.1016/j.ces.2011.11.036.

[54] B. González, W. Liu, D.S. Sultan, J.S. Dennis, The effect of steam on a synthetic Ca-based sorbent for carbon capture, Chem. Eng. J. 285 (2016) 378-383. doi:10.1016/j.cej.2015.09.107.

[55] R. Barker, The reversibility of the reaction $\mathrm{CaCO} 3 \leftrightarrow \mathrm{CaO}+\mathrm{CO} 2$, J. Appl. Chem. Biotechnol. 23 (1973) 733-742. doi:10.1002/jctb.5020231005.

[56] T. Shimizu, T. Hirama, H. Hosoda, K. Kitano, M. Inagaki, K. Tejima, A twin fluidbed reactor for removal of $\mathrm{CO} 2$ from combustion processes, Chem. Eng. Res. Des. 77 (1999) 62-68. doi:10.1205/026387699525882.

[57] A. Silaban, D.P. Harrison, High temperature capture of carbon dioxide: characteristics of the reversible reaction between $\mathrm{CaO}(\mathrm{s})$ and $\mathrm{CO} 2(\mathrm{~g})$, Chem. Eng. Commun. 137 (1995) 177-190. doi:10.1080/00986449508936375.

[58] S.K. Bhatia, Analysis of distributed pore closure in gas-solid reactions, AIChE J. 
31 (1985) 642-648. doi:10.1002/aic.690310414.

[59] G. Grasa, I. Martínez, M.E. Diego, J.C. Abanades, Determination of CaO carbonation kinetics under recarbonation conditions, Energy and Fuels. 28 (2014) 4033-4042. doi:10.1021/ef500331t.

[60] D. Mess, A.F. Sarofim, J.P. Longwell, Product layer diffusion during the reaction of calcium oxide with carbon dioxide, Energy and Fuels. 13 (1999) 999-1005. doi:10.1021/ef980266f.

[61] S.Y. Chuang, J.S. Dennis, A.N. Hayhurst, S.A. Scott, Kinetics of the chemical looping oxidation of $\mathrm{CO}$ by a co-precipitated mixture of $\mathrm{CuO}$ and $\mathrm{Al} 2 \mathrm{O} 3$, Proc. Combust. Inst. 32 (2009) 2633-2640. doi:10.1016/j.proci.2008.06.112.

[62] J.M. Valverde, P.E. Sanchez-Jimenez, L.A. Perez-Maqueda, Limestone calcination nearby equilibrium: Kinetics, $\mathrm{CaO}$ crystal structure, sintering and reactivity, J. Phys. Chem. C. 119 (2015) 1623-1641. doi:10.1021/jp508745u.

[63] J.C. Abanades, The maximum capture efficiency of $\mathrm{CO} 2$ using a carbonation/calcination cycle of $\mathrm{CaO} / \mathrm{CaCO} 3$, Chem. Eng. J. 90 (2002) 303-306. doi:10.1016/S1385-8947(02)00126-2. 


\section{CAPTIONS}

Figure 1. Conceptual scheme of the integrated configuration of CaL process into a cement plant.

Figure 2. XRD diffractogram of samples calcined at $900{ }^{\circ} \mathrm{C}$ in air and mixture of $\mathrm{CO}_{2} /$ air.

Figure 3. Conversion of raw meals during 7 cycles of calcination/carbonation. Calcination conditions: $\mathrm{T}$, calc $=875^{\circ} \mathrm{C}$ and pure air. Carbonation conditions: $\mathrm{T}, \mathrm{carb}=650^{\circ} \mathrm{C}$ and $10 \%$ $\mathrm{CO}_{2}$ in air.

Figure 4. Pore structure and specific surface area according to different calcination conditions.

Figure 5. XRD diffractogram of calcined samples at different temperatures.

Figure 6. (Left) Final conversion after 5 minutes of carbonation at every cycle of calcination/carbonation of the calcined sample. (Right) First carbonation after calcination in furnace without calcination in TG. Carbonation in the TGA at $650^{\circ} \mathrm{C}$ and $10 \% \mathrm{CO}_{2}$. Subsequent calcinations at $900{ }^{\circ} \mathrm{C}$ and $100 \%$ air.

Figure 7. Initial reaction rate according to the area obtained by $\mathrm{Hg}$ porosimetry.

Figure 8. (Left) First carbonation at different carbonation temperature in TG. (Right) Carbonation at $650^{\circ} \mathrm{C}$ at different number of cycle. $\left(\right.$ Calcination temperature $=900^{\circ} \mathrm{C}$ )

Figure 9. Arrhenius plot of $\mathrm{k}_{\mathrm{s}}, \mathrm{k}_{\mathrm{CaO}}$ and $\mathrm{D}$. Values of $\mathrm{k}_{\mathrm{s}, 0}, \mathrm{k}_{\mathrm{CaO}, 0} \mathrm{D}_{0}$ and respective activation energy are in the fitted equation.

Figure 10. Comparison of critical layer thickness (this work) and values from bibliography. 
Figure 1

$\mathrm{CO}_{2}$ rich gas

$\mathrm{CO}_{2}$ lean gas

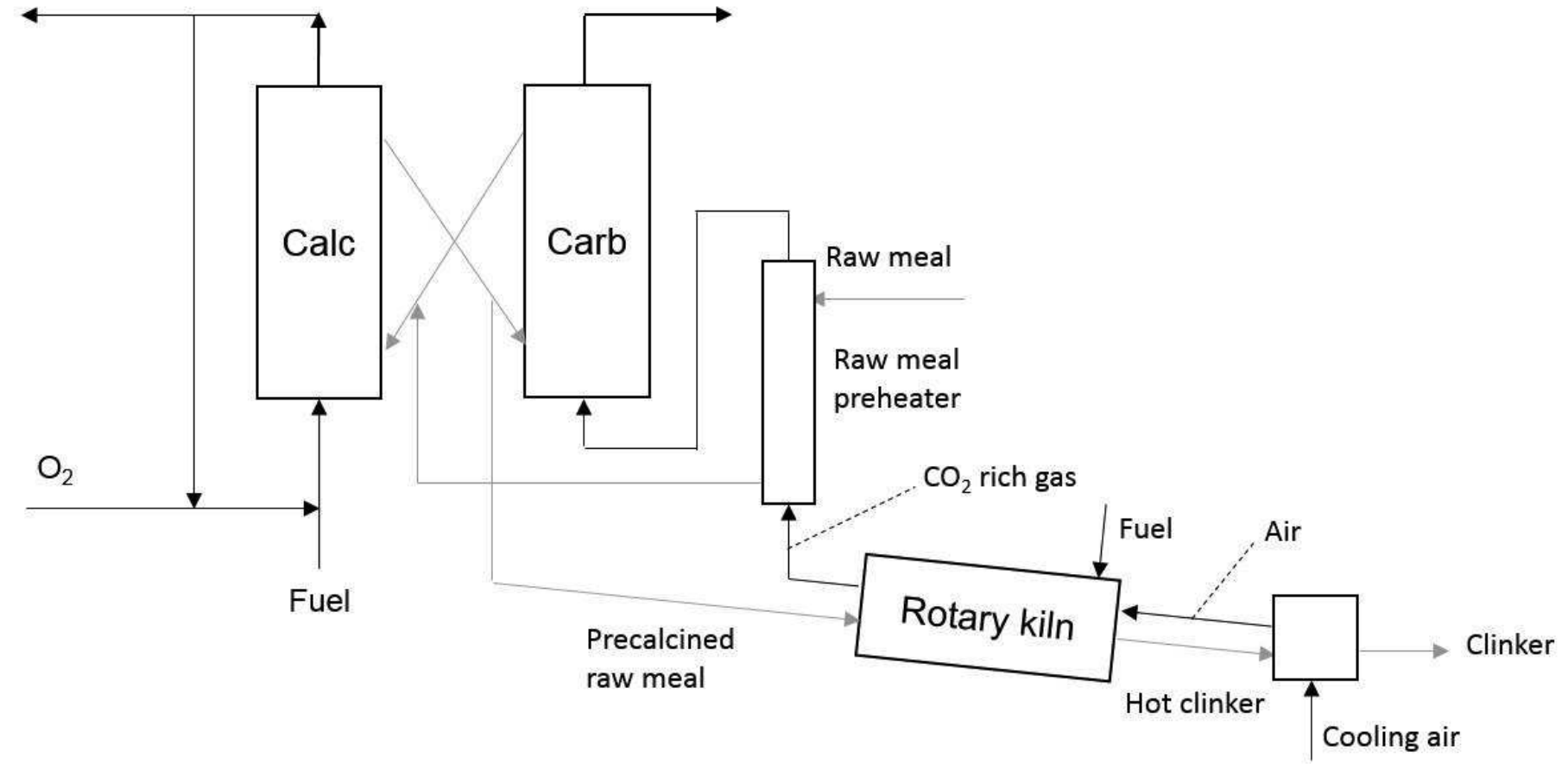


Figure 2

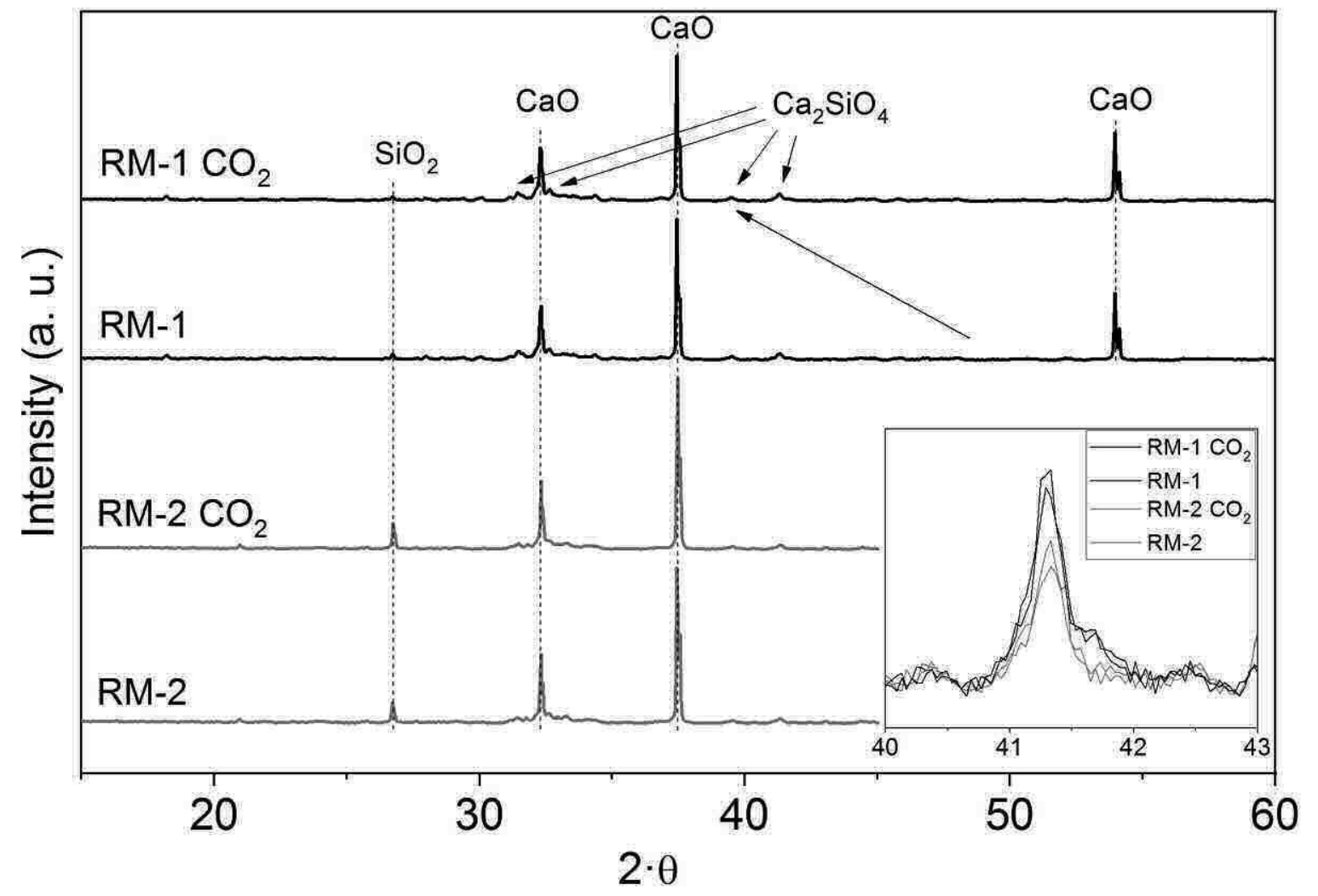


Figure 3

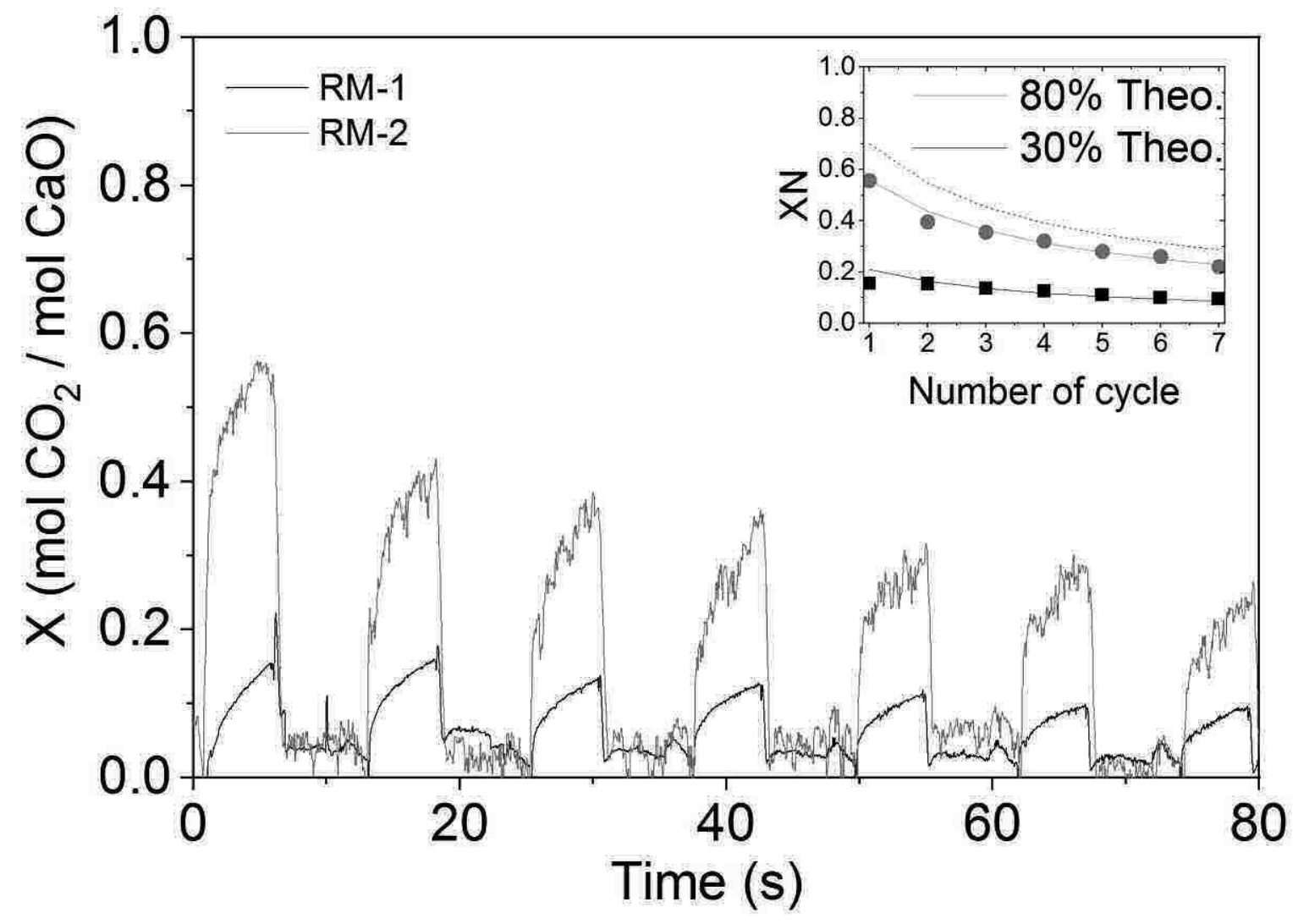


Figure 4

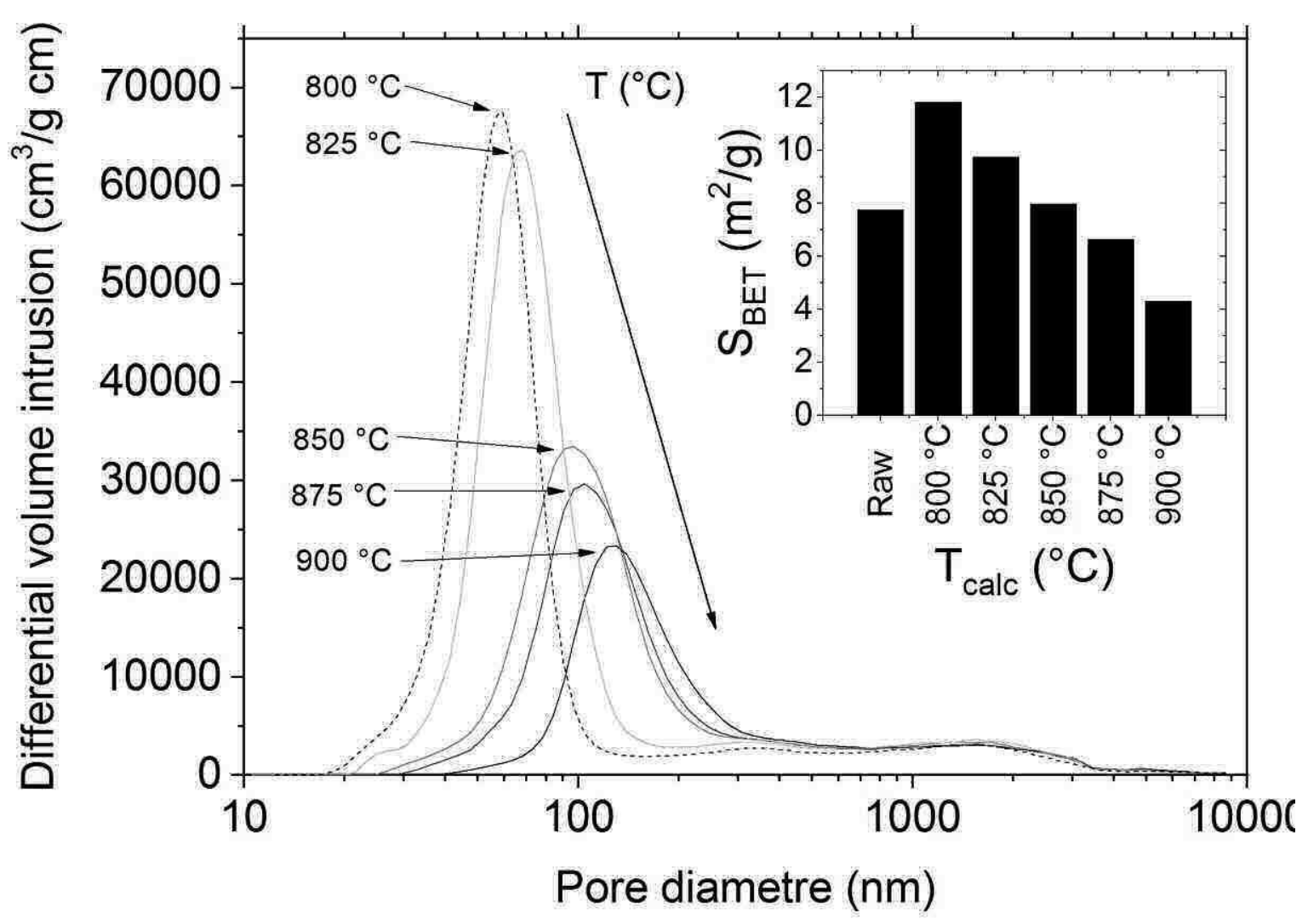



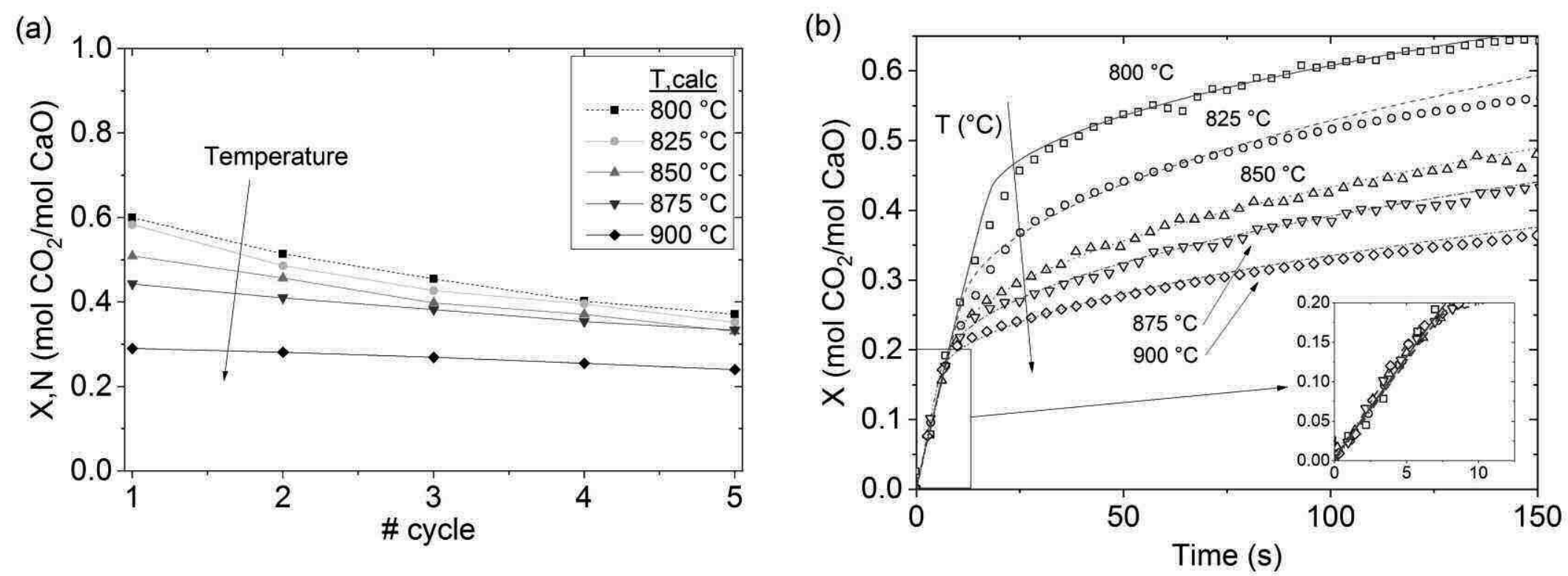
Figure 7

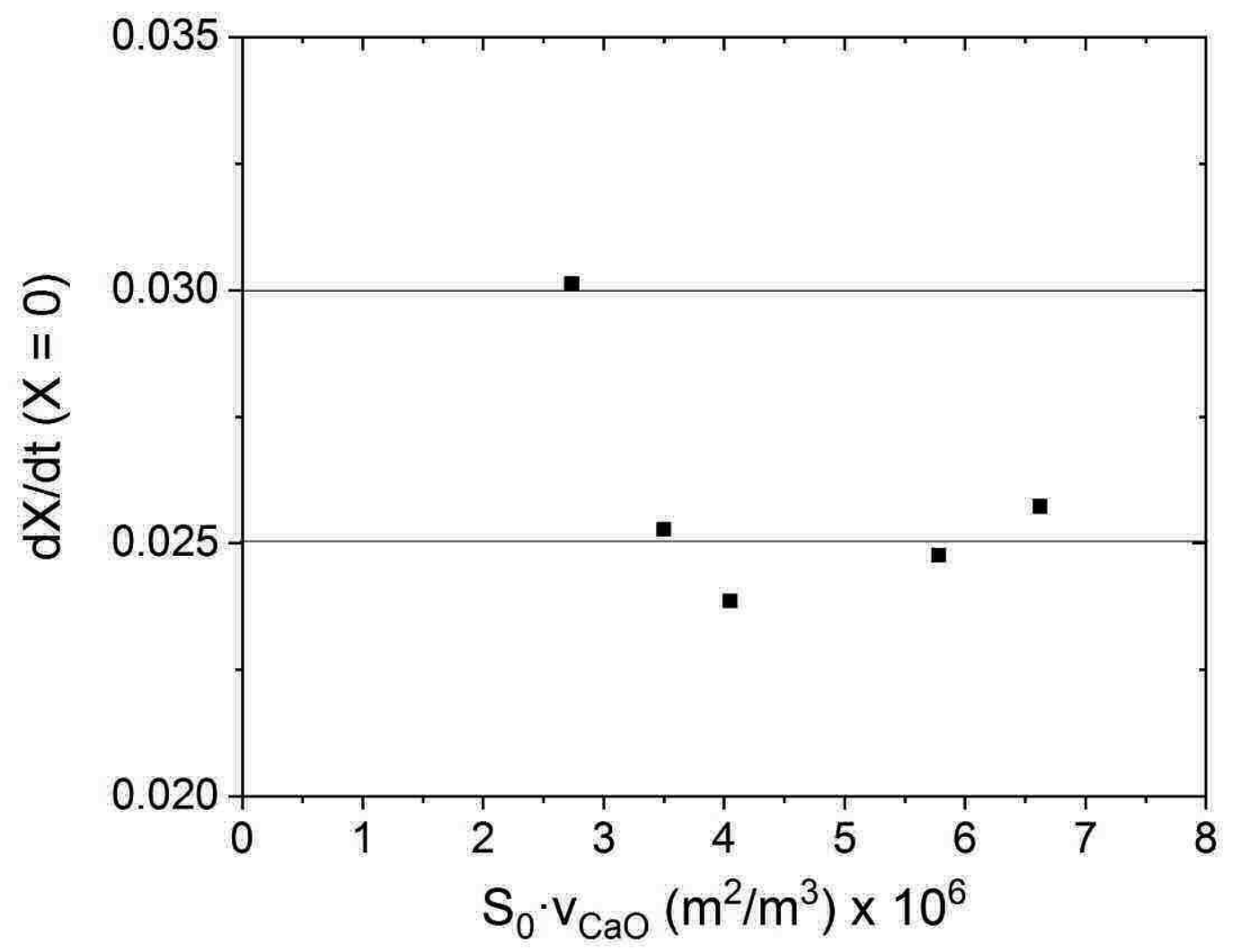


Figure 8
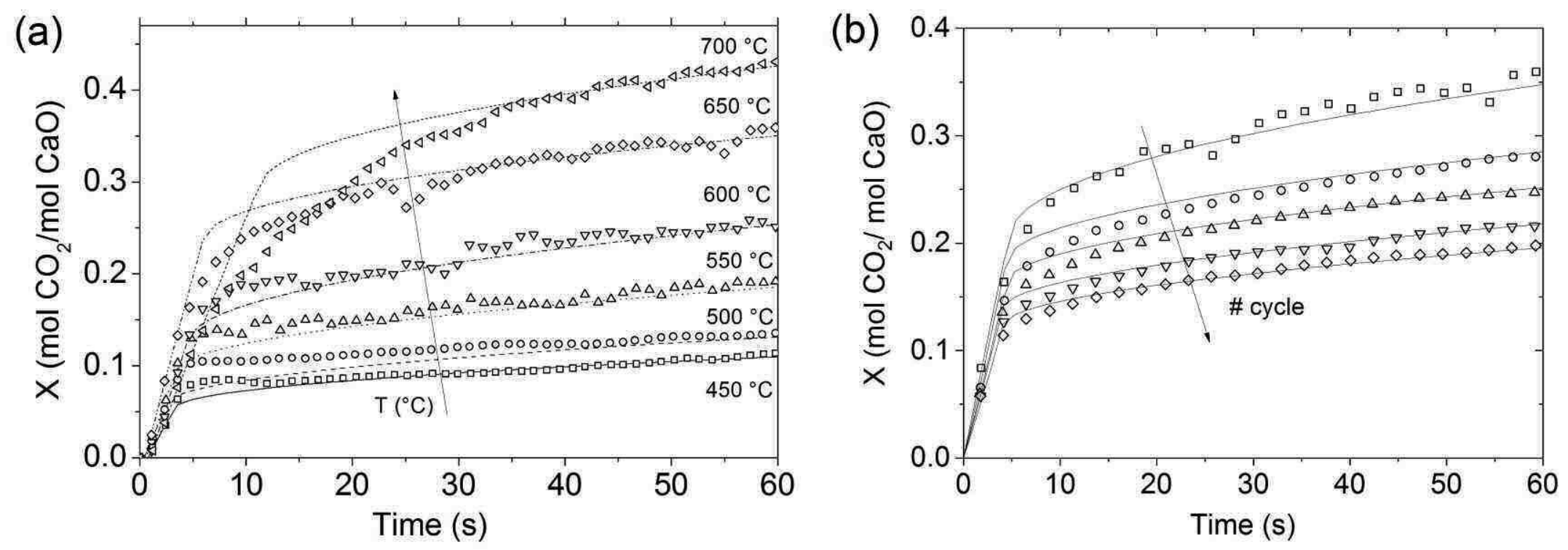
Figure 9

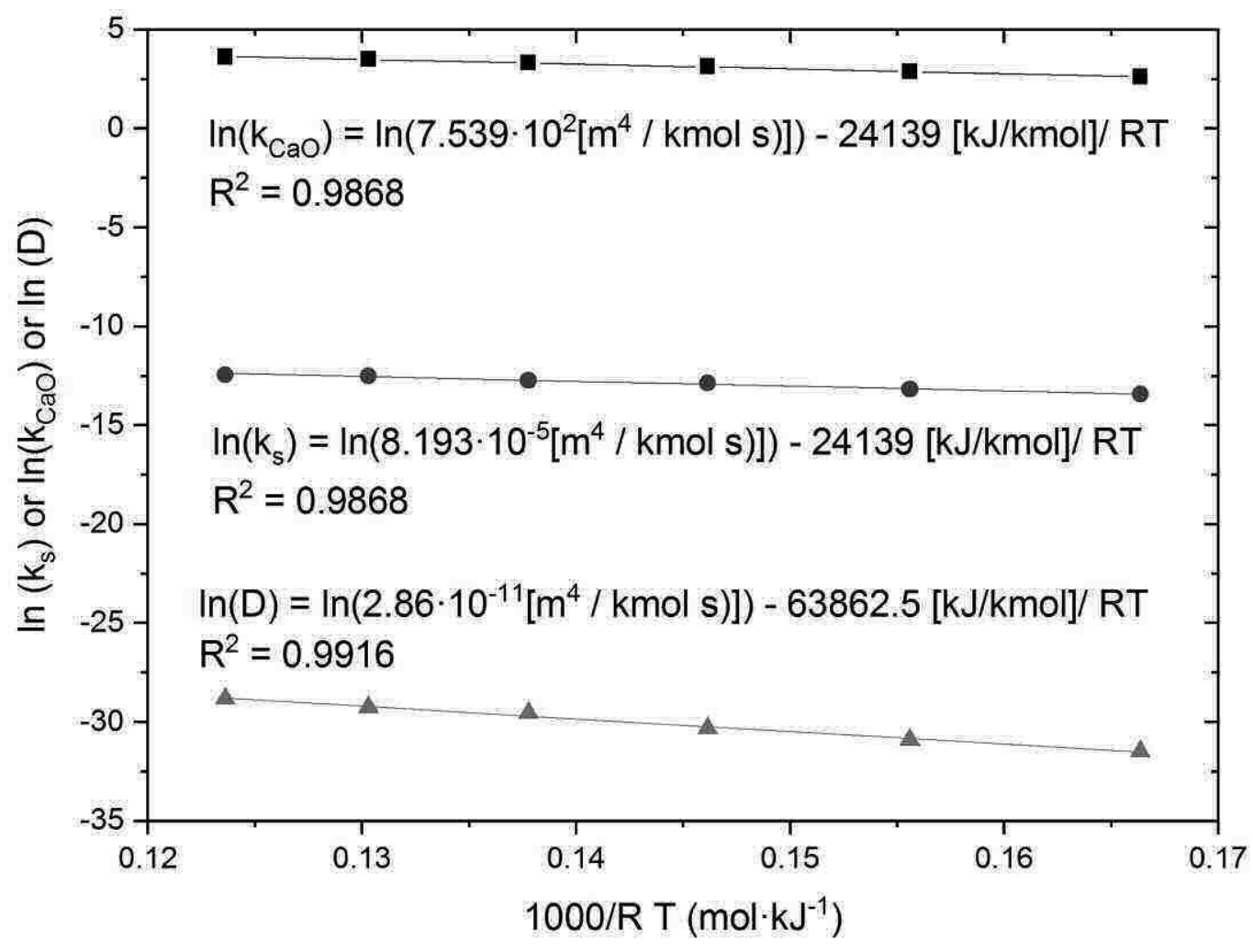


Figure 10

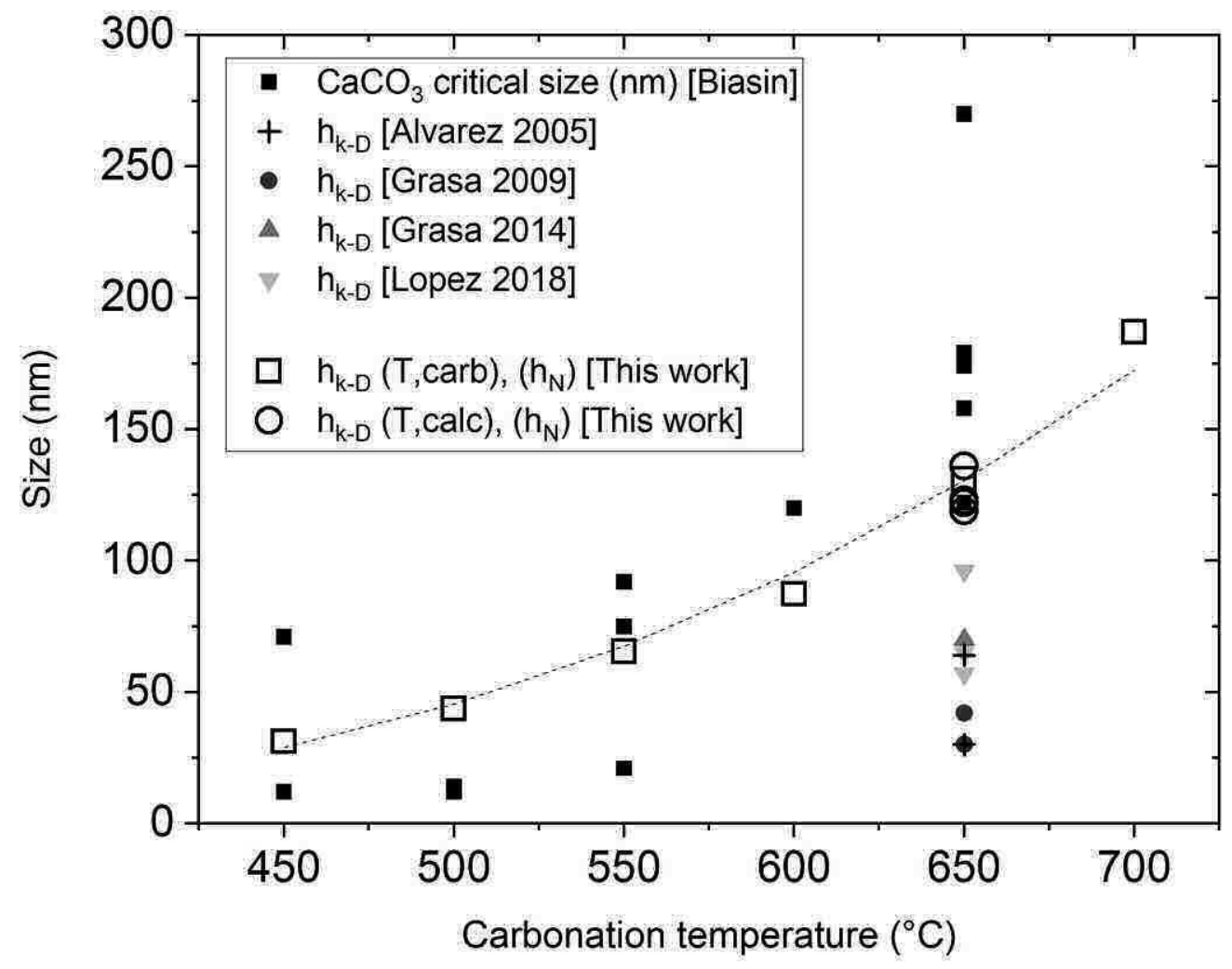

